\title{
Review
}

Francisco J. Sánchez-Gómez, Cristina Espinosa-Díez, Megha Dubey, Madhu Dikshit and Santiago Lamas*

\section{S-glutathionylation: relevance in diabetes and potential role as a biomarker}

\begin{abstract}
Glutathione is considered the main regulator of redox balance in the cellular milieu due to its capacity for detoxifying deleterious molecules. The oxidative stress induced as a result of a variety of stimuli promotes protein oxidation, usually at cysteine residues, leading to changes in their activity. Mild oxidative stress, which may take place in physiological conditions, induces the reversible oxidation of cysteines to sulfenic acid form, while pathological conditions are associated with higher rates of reactive oxygen species production, inducing the irreversible oxidation of cysteines. Among these, neurodegenerative disorders, cardiovascular diseases and diabetes have been proposed to be pathogenetically linked to this state. In diabetes-associated vascular complications, lower levels of glutathione and increased oxidative stress have been reported. S-glutathionylation has been proposed as a posttranslational modification able to protect proteins from over-oxidizing environments. S-glutathionylation has been identified in proteins involved in diabetic models both in vitro and in vivo. In all of them, S-glutathionylation represents a mechanism that regulates the response to diabetic conditions, and has been described to occur in erythrocytes and neutrophils from diabetic patients. However, additional studies are necessary to discern whether this modification represents a biomarker for the early onset of diabetic vascular complications.
\end{abstract}

Keywords: diabetes; glutathione; hyperglycemia; oxidative stress; posttranslational modification; signaling.

*Corresponding author: Santiago Lamas, Centro de Biología Molecular 'Severo Ochoa', Campus Universidad Autónoma, Nicolás Cabrera 1, E-28049, Madrid, Spain, e-mail: slamas@cbm.uam.es Francisco J. Sánchez-Gómez and Cristina Espinosa-Díez: Centro de Biología Molecular 'Severo Ochoa', Campus Universidad Autónoma, Nicolás Cabrera 1, E-28049, Madrid, Spain

Megha Dubey and Madhu Dikshit: Pharmacology Division, CSIRCentral Drug Research Institute, Lucknow, India

\section{Introduction into glutathione functions and activities}

\section{Physiology of glutathione}

Glutathione (GSH) is a tripeptide, $\gamma$-glutamyl-L-cysteinylglycine, ubiquitously detected in all mammalian tissues. It is preferentially generated in the liver, but it is synthesized by almost all cell types in its reduced form, GSH. The concentration of the disulfide form of glutathione (GSSG) is increased in response to oxidative stimuli (Kaplowitz et al., 1985). Glutathione is the predominant form, in the low millimolar (about $10 \mathrm{~mm}$ ) range while the oxidized form represents $<1 \%$ of the reduced form (Akerboom et al., 1982). The redox pair $2 \mathrm{GSH} / \mathrm{GSSG}$ has been considered a reporter of the redox homeostasis or oxidative stress. The 2GSH/GSSG molar ratio of unstressed wild-type cells is considered to be approximately 100-300:1, corresponding to redox potentials from $-220 \mathrm{mV}$ to $-240 \mathrm{mV}$. Recently it has been proposed that the $2 \mathrm{GSH} / \mathrm{GSSG}$ ratio could be significantly higher (Morgan et al., 2013).

\section{Functions of glutathione}

The two basic functions of glutathione are: the detoxifying function; and the regulation of the redox homeostasis. These comprise the detoxification of electrophilic compounds and free radicals and the regulation of the redox balance ( thiol status) depending on the $2 \mathrm{GSH} /$ GSSG ratio inside the cell (Meister and Anderson, 1983). However, other secondary functions have been described for glutathione as a reservoir of cysteine, as a modulator of some cellular processes (DNA synthesis, microtubularrelated processes and immune function) or as a regulator of nitric oxide homeostasis (Martinez-Ruiz and Lamas, 2005, 2007). In addition, during the past 15 years increasing evidence has accumulated regarding the importance 
of S-glutathionylation of proteins (Klatt and Lamas, 2000).

\section{Detoxifying function of GSH}

This is the classical function of glutathione. Many xenobiotics are compounds with high affinities for electrons. These electrons are donated by different proteins that act as nucleophilic electron donors, and therefore the function of these proteins is altered irreversibly. These compounds may form conjugates with GSH, either spontaneously or enzymatically catalyzed by GSH-S-transferase (Meister, 1988), and can be excreted out of the cells, and extracellularly cleaved by $\gamma$-glutamyltranspeptidase $(\gamma \mathrm{GT})$ (Meister and Anderson, 1983). Ultimately these conjugates are metabolized to mercapturic acid in the kidney.

Reactive oxygen species (ROS), as potentially toxic compounds, also need to be detoxified from the cells. These ROS [primarily superoxide $\left[\mathrm{O}_{2}^{-}\right]$and hydrogen peroxide $\left(\mathrm{H}_{2} \mathrm{O}_{2}\right)$ ] contribute themselves to the generation of other radicals or oxidative species, increasing the cellular state of oxidation. Glutathione contributes to the degradation of $\mathrm{H}_{2} \mathrm{O}_{2}$ through glutathione peroxidase ( $\mathrm{GPx}$ ), generating GSSG. Finally, the oxidized glutathione is recycled by glutathione reductase (GR). This mechanism is activated when $\mathrm{H}_{2} \mathrm{O}_{2}$ detoxification by catalase is overloaded (for example in pathological settings), or when this pathway is absent, as in mitochondria (Garcia-Ruiz and Fernandez-Checa, 2006). When GSSG recycling is overloaded, the concentration of GSSG becomes high enough to induce the formation of glutathione-protein adducts (PS-SG). This modification is able to alter the function of proteins, either inactivating or activating them, depending on the protein.

\section{Regulation of redox homeostasis (thiol status)}

As the major non-protein thiol present inside the cells, glutathione is the main regulator of the intracellular redox balance. This redox balance preserves the stability of the thiol status within cellular proteins, either by the above-mentioned detoxification function, or by the thioldisulfide exchange between proteins and glutathione catalyzed by thiol-transferases. The shift of the equilibrium depicted in reaction 6 (Figure 1) is dependent on the redox status of the cell determined by the ratio 2GSH/GSSG (Lu, 1999). This ratio also regulates a broad range of cellular processes, which are dependent on the specific proteins affected.

\section{Regulation of glutathione}

The regulation of glutathione levels is dependent on:

(i) the de novo synthesis;

(ii) the glutathione consumption, modified by its interaction with proteins, xenobiotics, and their export; and

(iii) the recycling of both the glutathione components from outside the cell as well as from the oxidized glutathione inside the cell.

\section{Synthesis of glutathione}

This synthesis is present in almost every tissue and cell type, but preferentially in the liver. The product of the synthesis is a tripeptide composed of glutamate, cysteine and glycine. In the first reaction, glutamate is conjugated with cysteine through the carboxyl group in the $\gamma$ position of the glutamate and the amino group of the cysteine; whereas in the second reaction the $\gamma$-glutamyl- $L$-cysteine reacts with the glycine to form $\gamma$-glutamyl-cysteinyl-glycine. Both reactions require adenosine triphosphate (ATP). The enzymes involved in the synthesis are glutamyl-cysteineligase or $\gamma$-glutamyl-cysteine synthetase (GCL/GCS) (Figure 1, reaction 1) and glutathione synthetase, (GS) (Figure 1, reaction 2) (Meister, 1974). GCL catalyzes the first step in the synthesis of glutathione. The enzyme has two subunits (heavy, Mr 73 000; and light, Mr 31 000). The heavy subunit (GCLc) accounts for the catalytic activity of the isolated enzyme and feedback inhibition by glutathione (Seelig et al., 1984). This subunit has been described to be induced under oxidative stress conditions (Lu et al., 1992). Insulin has also been described to induce the expression of GCLc (Kim et al., 2004). Therefore, this induction may be considered an initial response of the cells to the exposure of external insults. On the other hand, transforming growth factor $\beta 1$ represents one of the major repressors of GCLc mRNA (Jardine et al., 2002). These regulations are ruled mainly by the binding of transcription factors to antioxidant response element (ARE) boxes within the GCLc promoter (Wild et al., 1999; Jardine et al., 2002). Several transcription factors including nuclear factor erythroid 2-related factor 2 (Nrf2), activator protein 1(AP-1) family and nuclear factor $\kappa \mathrm{B}(\mathrm{NF} \kappa \mathrm{B})$ are involved in this regulation (Yang et al., 2005). GCLc may be also regulated at posttranscriptional levels. The activity of GCLc is also regulated by phosphorylation. Protein kinase A, protein kinase $\mathrm{C}(\mathrm{PKC})$ and $\mathrm{Ca}^{2+}$-calmodulin kinase II directly phosphorylate GCLc at serine and threonine residues in vitro and in culture cells (Sun et al., 1996). This 


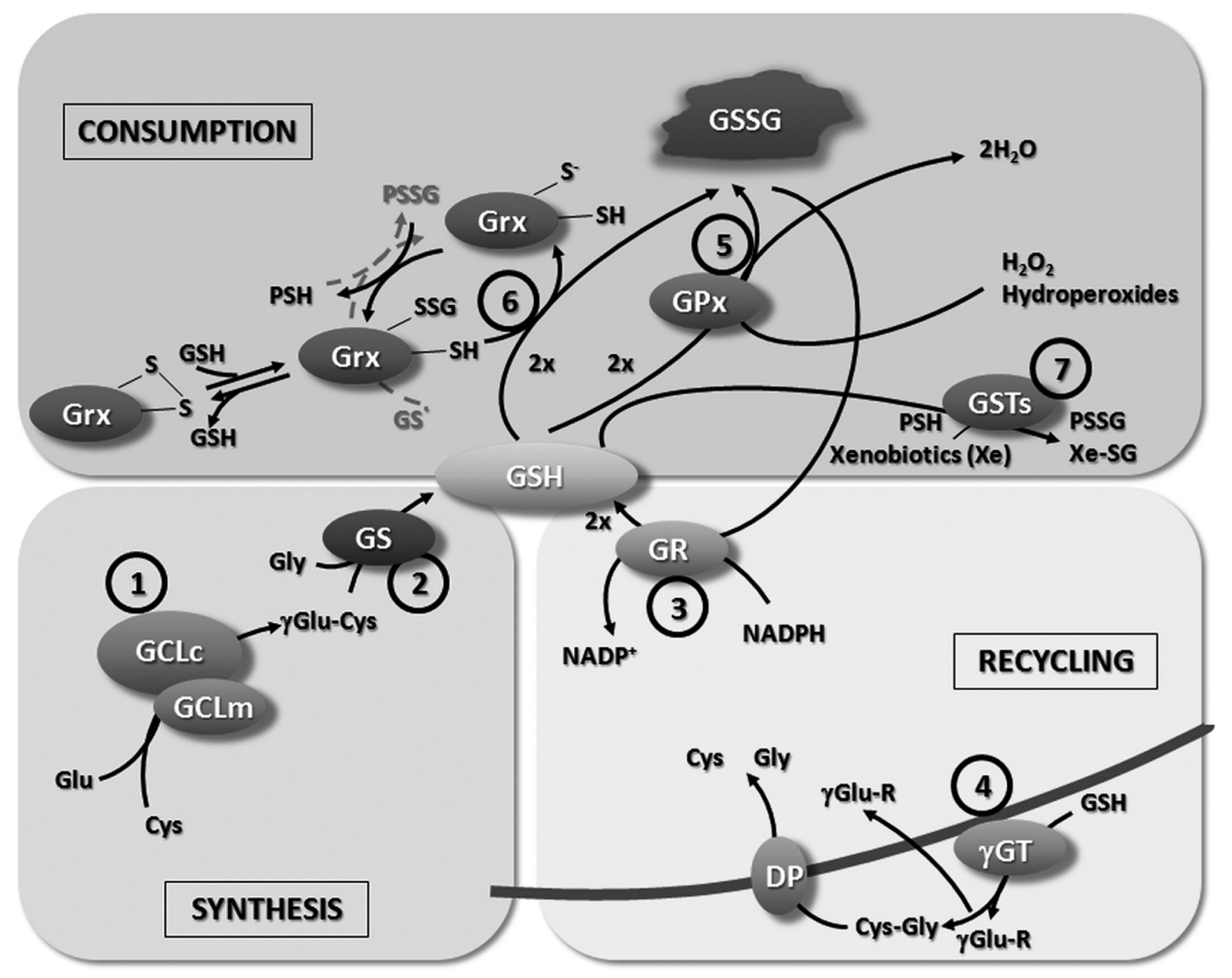

Figure 1 Regulation of GSH levels.

The levels of GSH are tightly regulated by different enzymes related to redox balance. The main input of GSH comes from the de novo synthesis, carried out by two serial reactions catalyzed by GCL (reaction 1) and GS (reaction 2). The GSH used in the cell can be recycled by GR (reaction 3), spending one molecule of NADPH to reduce one molecule of GSSG. Extracellular GSH is sequentially broken down by $\gamma$ GT and dipeptidase (reaction 4) into its amino acid components to be transported inside the cell and become available for de novo synthesis. Two molecules of GSH are used by GPx to reduce $\mathrm{H}_{2} \mathrm{O}_{2}$ and hydroperoxides, generating GSSG (reaction 5). The reduction of GS-protein adducts is catalyzed by Grxs at the expense of GSH (reaction 6). The detoxification of xenobiotic compounds and the formation of GSH protein adducts are carried out by GSTs using GSH molecules (reaction 7). Key: $\gamma \mathrm{GT}, \gamma$-glutamyltranspeptidase; GCL, glutamyl-cysteineligase; GR, glutathione reductase; Grxs, glutaredoxins; GSH, glutathione; GS, glutathione synthetase; GSSG, disulfide form of glutathione.

phosphorylation is present in non-stimulatory conditions and it suggests that GCLc activity may be basally under the influence of an inhibitory tone. GCLc is also cleaved by caspase-3 during apoptotic processes generating two peptides ( 60 and $13 \mathrm{kDa}$ ), preventing the association between GCLc and the light or modulatory subunit of GCL (GCLm) (Franklin et al., 2002). The N-terminal glycine of the $13 \mathrm{kDa}$ fragment has been predicted to become myristoylated, an observation proven in overexpression models, but not in apoptotic cells (Martin et al., 2008).

The light subunit does not exhibit catalytic activity by itself, but contributes to the activity of the heavy subunit by importantly affecting interactions of the substrate at the active site (Huang et al., 1993). These and other considerations point to a major regulatory function for GCLm in glutathione synthesis. Some of the above-mentioned stimuli could induce both, GCLc and GCLm (Wild et al.,
1999; Yang et al., 2005). However, there is some evidence supporting the specific up-regulation of GCLm. Thyroid hormone and cysteine deprivation induce GCLm expression (Dasgupta et al., 2007). Nrf1, Nrf2, AP-1, NFkB and c-Myc seem to be involved in the regulation of the promoter activity of the GCLm gene (Wild et al., 1999; Yang et al., 2005; Benassi et al., 2006). Interestingly, it has been shown that insulin was unable to change the levels of GCLm mRNA (Okouchi et al., 2006), while GCLc levels were affected by this stimulus in the same report.

The second reaction involved in glutathione synthesis is carried out by glutathione synthetase. This enzyme is a homodimer composed of two subunits of $52 \mathrm{kDa}$ (Polekhina et al., 1999) belonging to the ATP-grasp superfamily, as it presents the carboxylate-amine/thiol ligase activity (Galperin and Koonin, 1997). Regarding transcriptional regulation, the GS promoter is induced by AP-1, 
NFאB (indirectly through AP-1), Nrf1 and Nrf2 (Lee et al., 2005; Yang et al., 2005). Although GCL has been described as the rate-limiting enzyme in GSH generation, this second reaction can become limiting in some situations, such as when GCL reaction is under optimal conditions and GS levels are not sufficient to transform all the $\gamma$-glutamylcysteine produced by GCL (for example, when only GS is down-regulated or absent). In human skeletal muscle under physiological conditions, GS activity is only $36 \%$ higher than GCL activity. However, after skeletal muscle surgery, GS activity is selectively reduced, thus becoming limitant (Luo et al., 1998). Deficiency of GS in humans is associated with $25 \%$ of lethality in the neonatal period (Ristoff et al., 2001). Depending on the clinical manifestations, patients may suffer a mild condition, with alterations in enzyme stability (Spielberg et al., 1978) leading to hemolytic anemia. Moderately affected patients develop metabolic acidosis and urine excretion of 5-oxoproline. Severely affected patients also develop progressive dysfunction of the central nervous system.

\section{Recycling of consumed glutathione}

The recycling of GSH from GSSG occurs by the concourse of $\gamma$-glutamyl transpeptidase and GR. The latter is a homodimeric and ubiquitous flavin adenine dinucleotidecontaining enzyme (Williams, 1976). It catalyzes the reaction where one molecule of nicotin adenosin diphosphate (NADPH), acting as electron donor, converts GSSG into two molecules of glutathione (Figure 1, reaction 3) (Pai and Schulz, 1983). The function of the enzyme is to maintain the cellular ratio of $2 \mathrm{GSH} / \mathrm{GSSG}$ at high levels. A value of about 300:1 for the 2GSH/GSSG ratio has been reported in rat liver (Akerboom et al., 1982). GR is a member of the family of disulfide reductases, all of them flavin adenine dinucleotide-containing redox enzymes that interact with disulfide substrates (Williams, 1976). The enzyme has been identified as one of the target molecules of the widely applied antitumor drug bis-chloroethylnitrosourea (Frischer and Ahmad, 1977), and a target of ajoene, a compound present in the garlic extract. Its inactivation may result in a 400-fold increased activity of NADPH oxidase (NOX), generating superoxide (Gallwitz et al., 1999). As it is the case with many antioxidant enzymes, Nrf2 is a key regulator of GR expression (Harvey et al., 2009).

GSH concentration inside the cells also depends on the regeneration of glutathione adducted to cysteines of proteins and exported, a step catalyzed by $\gamma$-glutamyl transpeptidase. This enzyme catalyzes the transfer of the $\gamma$-glutamyl moiety from glutathione,
glutathione-S-conjugates and other $\gamma$-glutamyl compounds to acceptors such as amino acids, dipeptides, and $\mathrm{H}_{2} \mathrm{O}$ (Tate and Meister, 1981) (Figure 1, reaction 4). Although it is a recycling enzyme, its activity is directly related to the de novo synthesis of glutathione, as the products of its catalyzed reaction are cleaved by membrane-bound dipeptidases into the constituent amino acids that will be reused to produce glutathione. Therefore, its activity contributes to the regeneration of cysteine, the limiting substrate for GSH biosynthesis (Zhang et al., 2005). $\gamma$ GT is located at the external surface of the plasma membrane, although it exists in other localizations, such as blood serum (Whitfield, 2001). The $\gamma$ GT-deficient mice show elevated blood and urine levels of glutathione, cysteine deficiency, decreased tissue glutathione content, and increased susceptibility to oxidative stress, all of which are reversible by treatment with $N$-acetylcysteine (NAC) (Griffith and Meister, 1980; Lieberman et al., 1996; Jean et al., 2002). The expression of $\gamma \mathrm{GT}$ is modified under certain conditions, such as liver and cardiovascular disease, diabetes mellitus and cancer (Vanderlaan and Phares, 1981; Hanigan, 1998), where $\gamma \mathrm{GT}$ is induced by oxidants.

\section{Consumption of glutathione}

The detoxification of hydroperoxides in cells is carried out by glutathione peroxidases. These proteins were the first seleno-enzymes that were discovered in mammals (Flohe et al., 1973). The classical glutathione peroxidase (GPx-1), was the first described as an erythrocyte enzyme that specifically reduces $\mathrm{H}_{2} \mathrm{O}_{2}$ by glutathione (Mills, 1957) (Figure 1 , reaction 5), but later it was also shown to reduce a broad scope of organic hydroperoxides (Little and O'Brien, 1968). In mammals up to eight GPxs have been described; most of them are selenoproteins (mammalian GPx-1,-2, -3 and -4; and depending on the species GPx-6), while in the remaining two or three variants the active site of selenocysteine is replaced by cysteine. All have the ability to reduce hydroperoxides at the expense of thiols. Bioavailable selenium is a crucial factor for the biosynthesis of the selenoprotein members of the family (Brigelius-Flohe, 2006). The regulation of these enzymes has been related to Nrf2 induction (Cho et al., 2005), and their expression is related to NF $\kappa B$-mediated anti-inflammatory responses (Banning and Brigelius-Flohe, 2005). The expression of glutathione peroxidases has been described in tumor processes, such as colon adenocarcinoma (Lin et al., 2002).

Other enzymes related to glutathione consumption are the glutaredoxins (Grxs). They are glutathionedisulfide oxidoreductases reported to catalyze a variety 
of glutathione-dependent thiol-disulfide exchange reactions (Mieyal et al., 2008). It is interesting to note that the configuration of Grxs varies between organisms. Humans present Grx-1, -2, -3 and Grx4 isoforms. Grxs catalyze the reversible reduction of protein disulfides utilizing both cysteinyl residues in their active site, transferring two hydrogen atoms to protein disulfide (Figure 1, reaction 6). As a result, the catalytic domain of Grxs forms a disulfide that would be recovered by spending two molecules of glutathione (Lillig et al., 2008). Protein deglutathionylation has received significant attention because of its regulatory roles in redox signaling transduction and sulfhydryl homeostasis (Dalle-Donne et al., 2008). Grxs are involved in relevant functions, such as donating electrons to ribonucleotide reductase (Holmgren, 1976) and reversible glutathionylation, catalyzing both the formation of glutathione adducts with proteins, such as glyceraldehyde 3-phosphate dehydrogenase (GAPDH), actin and protein tyrosine phosphatase 1B (PTP1B) (Starke et al., 2003), and reduction of mixed disulfides between protein thiols and glutathione (Yoshitake et al., 1994), as Ras, protein phosphatase 2 (PP2A), apoptosis signal-regulating kinase 1 (ASK-1), PTP1B, actin and procaspase-3 (Barrett et al., 1999; Adachi et al., 2004; Pan and Berk, 2007; Wang et al., 2007). The formation of glutathione adducts in proteins is produced in the presence of thiyl radical (GS), nitrosoglutathione and GSSG (Starke et al., 2003) (Figure 1, reaction 6, light arrows). Concomitantly, these modifications induce changes in proteins that may result in disease development such as diabetes, atherosclerosis lung diseases, Alzheimer's disease and cancer.

Glutathione transferases (GSTs) represent another family of enzymes that regulate free glutathione levels inside the cell. GSTs are a superfamily of multifunctional proteins with fundamental roles in the cellular detoxification of a wide range of exogenous and endogenous compounds. They catalyze the formation of adducts of glutathione with electrophilic compounds that are exported out of the cell (Coleman et al., 1997) (Figure 1, reaction 7). They can also act as peroxidases and thiol transferases (Bartling et al., 1993; Board et al., 2000). Human GSTs are divided into two groups: microsomal and cytosolic. The first group is composed of three different isoforms designated 1, 2 and 3, is responsible for the endogenous metabolism of leukotrienes and prostaglandins (Jakobsson et al., 1999). Cytosolic GSTs are grouped into seven classes: $\alpha, \mu, \omega, \pi, \sigma, \theta$ and $\zeta$ (Mcllwain et al., 2006). All these enzymes belong to phase II detoxifying proteins and almost all of them are regulated by the Nrf2 transcription factor (for a review, see Hayes et al., 2005). In addition to the main detoxifying function described for these proteins, it has been reported that the class $\pi$ of GST is able to S-glutathionylate 1-cys-peroxiredoxin and aldose reductase at previously sulfonated cysteine residues (Manevich et al., 2004). Little has been published regarding the role of GST-mediated S-glutathionylation and diseases. Recently, Kim and colleagues have described that overexpression of GST omega is able to restore the S-glutathionylation of the ATP synthetase $\beta$ subunit, recovering its activity and decreasing the Parkinson phenotype in a Drosophila model (Kim et al., 2012a). However, it remains unclear whether this S-glutathionylation is related to the development of GST-associated diseases, such as kidney, lung and gynecological cancer, as well as smoke-associated cardiovascular risk, among others (Ueda et al., 2003; Stephens et al., 2008).

\section{Role of reactive oxygen species in diabetes}

\section{Sources of reactive oxygen species in diabetes}

Hyperglycemia, lack of insulin action and insulin resistance pave the way for the development of severe diabetic pathological conditions, such as diabetic nephropathy, retinopathy and other cardiovascular complications. While there is no unique cause for the onset of diabetes, many of its complications are connected with the generation of ROS (Giacco and Brownlee, 2010). The sources involved in ROS generation during diabetes include different proteins and compartments of the cell (Figure 2). Mitochondria may generate ROS through complex I (Boveris, 1977), complex III (Raha et al., 2000), $\alpha$-ketoglutarate dehydrogenase (Tretter and Adam-Vizi, 2004) (although it has been suggested that its ROS generation should be included in that of complex I), aconitase (Vasquez-Vivar et al., 2000) and mitochondrial p66Shc protein (Pellegrini et al., 2007).

In diabetes, the activation of PKC is considered as a hallmark of diabetic complications. PKC is activated by diacylglycerol, induced by mitochondrial ROS inhibition of GAPDH. In addition, PKC activation has been linked with a decrease of NO (nitric oxide) and cyclic guanosine monophosphate generation (Craven et al., 1994), an increase of transforming growth factor $\beta 1$ (Kanwar et al., 2008), and NFKB (Yerneni et al., 1999). Furthermore, PKC activation has been described to induce NADPH oxidase activity and therefore to increase ROS 


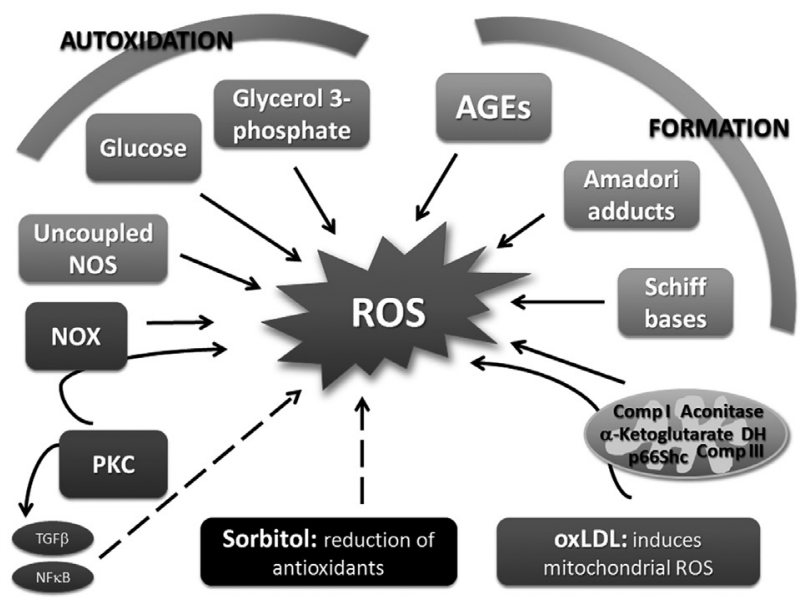

Figure 2 Reactive oxygen species (ROS) generation in diabetes. The different sources of ROS generation in diabetes are depicted. Some of these ROS are produced during the formation of advanced glycation end products, Amadori adducts and Schiff bases. The autoxidation of glucose and glycerol 3-phosphate is also able to produce ROS. In addition other proteins and protein complexes as uncoupled of nitric oxide synthase, NADPH oxidases, mitochondrial complex I and III, $\alpha$-ketoglutarate dehydrogenase, p66Shc and aconitase also contribute to ROS formation. Protein kinase $\mathrm{C}$ may indirectly participate in the formation of ROS. Sorbitol induces the reduction of antioxidants, contributing to ROS accumulation. Oxidized low-density lipoprotein particles may also induce mitochondrial ROS formation.

production, generating a feedback loop (Inoguchi et al., 2003). NADPH oxidases have also been implicated in diabetes, their increased expression having been reported in diabetic rat vessels (Hink et al., 2001). Hyperglycemia also enhances the preassembly of NOX and increases $\mathrm{p} 47^{\text {Phox }}$ translocation to the membrane in neutrophil-like HL-60 cells (Omori et al., 2008). The uncoupling of nitric oxide synthase (NOS) has also been described in diabetic rats, directly relating it to ROS production (Koo and Vaziri, 2003). As we know now, ROS may contribute to the inactivation of endothelial NOS (eNOS) by promoting its S-thiolation-mediated uncoupling and the subsequent generation of superoxide anions $\left(\mathrm{O}_{2}^{-*}\right)$ (Chen et al., 2011).

The excess glucose present in diabetic conditions may be converted by autoxidation to $\alpha$-ketoaldehydes, $\mathrm{H}_{2} \mathrm{O}_{2}$ and free radical intermediates (Thornalley et al., 1984). The $\mathrm{H}_{2} \mathrm{O}_{2}$ generated is able to inactivate GAPDH inducing glyceraldehyde 3-phosphate accumulation. In addition, glyceraldehyde 3-phosphate can be autoxidized to form again $\alpha$-ketoaldehydes and $\mathrm{H}_{2} \mathrm{O}_{2}$, generating a feedback loop. This accumulation may also inhibit insulin secretion, increasing glucose levels even further (MacDonald et al., 2006).
Other sources of ROS include the generation of advanced glycation end products (AGEs), which are molecules generated by the interaction of sugars and free amino groups in an enzyme-independent manner. ROS are produced during the formation of AGEs (Wolff and Dean, 1987), Schiff bases (Namiki et al., 1977) and Amadori adducts (Hodge, 1955). The binding of AGEs to their receptors (RAGE) also induces the formation of ROS (Kovacic and Somanathan, 2011).

Sorbitol may also act as an indirect ROS generator. Its formation from glucose requires NADPH, the same cofactor that GR uses to recycle GSSG, and therefore it may reduce the concentration of antioxidant defenses. Sorbitol is oxidized to fructose, a substrate of complex I in the mitochondrial transport chain, and one of the sources of superoxide. Finally, low-density lipoproteins (LDLs), one of the lipid components of blood flow, accumulate under diabetic conditions. When oxidized they may induce mitochondrial ROS production in endothelial cells, resulting in cellular apoptosis through the activation of the Bax apoptotic pathway (Cheng et al., 2007), with activation of mitochondrial complex II, superoxide radical generation, eNOS uncoupling and NOX activation (Takabe et al., 2010). Collectively these reports demonstrate that the generation of ROS is a multifactorial feature of diabetes. This implies that the prevention and/or treatment of ROS-induced effects in this disease should take into account the source as well as the organ, tissue or cell type affected.

The generation of ROS may trigger tissue damage that finally results in organ-specific pathologies. Germane to diabetes are atherosclerosis, nephropathy, retinopathy, nerve dysfunction and vasomotor dysfunction. The latter is closely related to endothelial dysfunction, a major consequence of reduced NO bioavailability. ROS may produce a decrease in NO bioavailability in several ways:

(i) reacting directly with NO, due to the reaction between superoxide and NO, generating peroxynitrite;

(ii) inactivating eNOS, the main enzyme involved in the endothelial synthesis of NO;

(iii) altering the availability of NOS substrates and cofactors, such as L-arginine and tetrahydrobiopterin $\left(\mathrm{BH}_{4}\right)$; and

(iv) inducing lipid peroxidation that interferes with receptor-dependent activation of eNOS (Onozato et al., 2002).

Tetrahydrobiopterin is the electron donor to oxidize L-arginine, and subsequently is reduced by eNOS flavins. When tetrahydrobiopterin is limiting, electrons are transferred 
from eNOS flavins and donated directly to $\mathrm{O}_{2}$ to form superoxide (Alp and Channon, 2004).

$\mathrm{H}_{2} \mathrm{O}_{2}$ has been considered a potential endotheliumderived hyperpolarizing factor (Matoba et al., 2002) and may alter specific redox-sensitive signals. ROS play an essential role in atherosclerotic events, due in part to the promotion of inflammation through the activation of $\mathrm{NF}-\mathrm{\kappa B}$. This activation induces the release of proinflammatory cytokines, prostaglandins and interleukins, all of them contributing to the infiltration of macrophages in the endothelium. NOXs have been proposed as major sources of these ROS (Ginnan et al., 2008). Nevertheless, ROS-induced S-glutathionylation may also inhibit NF $\mathrm{BB}$ activation (see below).

AGEs present in blood are processed by the kidneys before excretion. They can interact with their receptor (RAGE) and induce inflammatory responses and ROS generation (Schmidt et al., 1995), cardinal features of diabetic nephropathy. In vivo experiments have demonstrated that the AGE-RAGE interaction generates superoxide and may contribute to angiopathy development in type 2 diabetes (Penfold et al., 2010). Further, in diabetic patients, glycated albumin induces ROS production in endothelial cells (Rodino-Janeiro et al., 2010). These findings support the unpublished data from our lab, where we have observed how in the kidney of diabetic 16-weekold mice, the production of superoxide is significantly increased compared to lean mice. Consistently, GCLc mRNA levels were significantly decreased in the kidney, supporting the notion of the presence of impaired antioxidant capacity in diabetes.

Diabetic retinopathy is also associated with the presence of microvascular disease and associated with endothelial dysfunction. Retinal membranes are rich in polyunsaturated fatty acids, compounds that are highly susceptible to oxidation. Diabetic retinopathy is considered a low-level chronic inflammatory disease linked to cytokine release and excessive ROS (Duh et al., 2002). Altogether, such evidence supports the critical role of ROS production in the initiation and prevalence of diabetic complications, such as increased endothelial vasomotor tone, atherosclerosis, nephropathy and retinopathy, among others. In these conditions, the reduced bioavailability of NO and antioxidant defenses are crucial factors forestalling the balance in ROS production and vascular tone.

The role of ROS in signal transduction is now a well accepted concept. This has been supported by the characterization of $\mathrm{H}_{2} \mathrm{O}_{2}$ as an endogenously-generated second messenger (Suh et al., 1999). This generation in combination with its thermodynamic properties provides
$\mathrm{H}_{2} \mathrm{O}_{2}$ with the stability and potential for oxidation to represent an appropriate oxidative messenger (Forman et al., 2010). The main mechanism of signaling is carried out through the cysteine oxidation to its sulfenic form, a low stable state that may evolve into modifications such as S-glutathionylation, disulfide bridges and overoxidation to sulfinic and irreversible sulfonic forms of the cysteines. Oxidation has been involved in the regulation of the activity of several phosphatases including the phosphatase and tensin homolog (PTEN). Insulin administration to normal mice induces ROS production concomitantly with PTEN oxidation and downstream activation of kinases such as protein kinase B (PKBAkt). In addition, in GPx1 KO mice, ROS generation is increased in response to insulin and insulin receptor substrate 1 (IRS-1). Phosphatidylinositol 3-kinase (PI3K) and Akt are up-regulated. These effects were reverted by antioxidants (Loh et al., 2009) supporting the role of redox-mediated insulin signaling. The overexpression of GPx1 has been associated with the development of insulin resistance and obesity (McClung et al., 2004). Altogether this illustrates the essential role of ROS both in the signaling events as well as in the development of pathological disorders induced during alterations of glucose homeostasis.

\section{Role of glutathione in diabetic antioxidant defense}

In addition to the oxidative stress observed in almost all cells and tissues associated to diabetic complications, a general decrease in antioxidant defenses has been reported in a number of publications. The redox balance, and particularly the GSH state in these pathologies, is considered a critical parameter of the antioxidant machinery. Decreased levels of GSH in alloxan-induced diabetic rabbits were detected in aortic endothelial cells (Tagami et al., 1992). Streptozotocin is a type 1 diabetes inductor that produces the loss of $\beta$-cell islets in pancreas. In streptozotocin-induced diabetic rats, decreased levels of GSH in the renal cortex, brain, liver and blood have been reported. In addition, the activity of antioxidant enzymes such as superoxide dismutase, catalase and GPx, among others, has been found to be down-regulated (Tagami et al., 1992; Obrosova et al., 2003; Hong et al., 2004; Mastrocola et al., 2005; Lu et al., 2008). Alterations in the 2GSH/GSSG ratio are a common signature of diabetes-related oxidative stress and are believed to account for the associated protein dysfunction. During recent years, significant efforts have been made in the 
development of antioxidant agents and therapies in an attempt to decrease or revert the pathological features present in diabetic complications. The direct administration of GSH has been shown to promote improvements in diabetic cataractogenesis and nephropathy models (Ross et al., 1983; Morocutti et al., 1998). Organic and inorganic compounds such as lipoic acid, vitamin-E, melatonin, isoflavones and resveratrol have been studied in this regard. All of them have shown beneficial effects as antioxidant agents, increasing the levels of either glutathione or antioxidant enzymes (Obrosova et al., 2003; Hong et al., 2004; Lu et al., 2008). The mechanism by which glutathione concentration is reduced remains unclear, but both the synthesis and the recycling seem to be altered.

Overall, evidence strongly suggests that in diabetes oxidative stress contributes to abrogate general antioxidant defenses and reduces the $2 \mathrm{GSH} / \mathrm{GSSG}$ ratio, supporting the concept that diabetic complications are closely related to these changes.

\section{S-Glutathionylation in diabetes}

S-glutathionylation has been encountered in association with a wide range of diseases, including cancer, lung disease, cardiovascular diseases, diabetes (Mieyal et al., 2008) and neurodegenerative diseases (Sabens Liedhegner et al., 2012). The same target proteins may be found in more than one disease, depending on the model of study. It is also possible that S-thiolation of a protein affecting a given specific pathway exerts different effects depending on the cell type or tissue. However, a common feature of all of the aforementioned conditions is the increased levels of oxidative stress.

As already mentioned, in diabetic conditions, GSH concentration is reduced and GSSG increased. It is believed that accumulation of GSSG within the cell, promotes the formation of mixed disulfides between protein thiols and GSSG, either via thiol-disulfide exchange reactions and/or via Grxs or GSTs-mediated activity. Interestingly, a recent report has provided new data suggesting that GSSG is specifically transported inside of vacuoles in yeast by the $\mathrm{ABC}-\mathrm{C}$ transporter, thus profoundly altering the 2GSH/GSSG ratio in the cell cytoplasm and suggesting that the real $2 \mathrm{GSH} / \mathrm{GSSG}$ ratio is much higher and more stable than initially suspected (Morgan et al., 2013). In addition to this ratio, the content of PS-SG may be a better indicator of oxidative stress, as it is less prone to be modified by GR-mediated enzymatic reduction (Mannervik and Axelsson, 1975).

\section{S-glutathionylation and signaling cascades involved in diabetic events}

The formation of glutathione adducts has been reported at several steps of the pathway involved in insulin signaling. In addition, other proteins related to the metabolic regulation of this pathway, such as aldose reductase, have been shown to be modified by S-glutathionylation.

Insulin signaling is initiated by the interaction of the insulin molecule and its receptor (Figure 3). This binding triggers the activation of downstream protein kinases. The initial step involves the phosphorylation of the insulin receptor, an event regulated by protein tyrosine phosphatase 1B (PTP1B) and demonstrated both in vitro and in cellular models (Goldstein et al., 2005). The activity of this phosphatase or its genetic manipulation can modify insulin signaling (Tonks, 2003). In vitro experiments have demonstrated that PTP1B is oxidized by superoxide anion and S-glutathionylated at residue C215, leading to decreased activity (Barrett et al., 1999). These evidences have provided a basis on which to consider PTP1B a target for therapeutic approaches in diabetes (Goldstein, 2001; Tonks, 2003).

The PI3K-Akt pathway plays a central role in the signaling related to diabetes due to the activation of its different subunits in response to insulin initiation of the cascade. PI3K catalyzes the formation of phosphatidylinositol-(3,4,5) triphosphate, which induces Akt recruitment to the membrane. Although PI3K has not been found to be S-glutathionylated, PTEN, which dephosphorylates PIP3 at 3' phosphate to produce PIP2, has been shown to suffer S-glutathionylation in hepatocytes from rats fed with a high-fat diet (Alisi et al., 2012). Signaling proteins situated downstream of the PI3K pathway have been reported to be S-glutathionylated in diabetic conditions. Akt is early downstream and is involved in glucose metabolism, cell death and vascular tone; alterations in Akt function have been reported in diabetic models (Song et al., 2007). Although there is no direct evidence of Akt S-glutathionylation, $\mathrm{H}_{2} \mathrm{O}_{2}$-induced inactivation of Akt has been described to be reversed by Grx, suggesting that Akt can be inactivated by S-glutathionylation (Murata et al., 2003). Downstream of Akt is the inhibitor of the nuclear factor kappa-B kinase $\beta$ subunit (IKK $\beta$ ), whose regulation is a main event in insulin resistance in diabetes (Arkan et al., 2005). IKK $\beta$ becomes S-glutathionylated in retinal cells in basal conditions (Shelton et al., 2009). Finally, $\mathrm{NF \kappa B}$ remains an essential effector in this signaling pathway. IKK $\beta$-mediated phosphorylation of inhibitor $\mathrm{\kappa B}$ promotes its subsequent ubiquitination and degradation, releasing $\mathrm{NF} \kappa \mathrm{B}$ for nuclear translocation, binding to DNA 


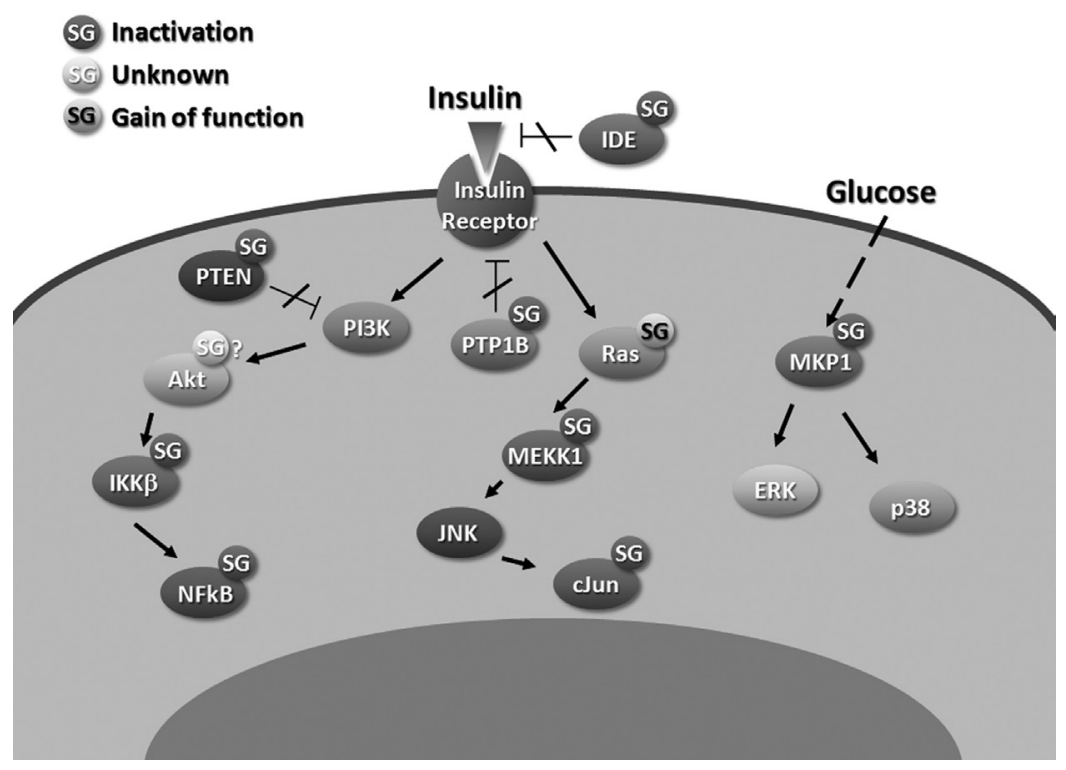

Figure 3 S-glutathionylation of proteins involved in signaling cascades related to the development of diabetes. Proteins from different signaling pathways involved in diabetes have been described to be S-glutathionylated, including the PI3K-Akt and Ras- mitogen activated protein kinase (MAPK)/ extracellular signal-regulated kinase kinase (MEKK) pathways. Redox- sensitive proteins as protein-tyrosine phosphatase $1 \mathrm{~B}$ and mitogen-activated protein kinase phosphatase 1 have been identified as S-thiolated proteins. Different colors in the 'SG' molecules indicate the differential effect that this S-glutathionylation exerts on the modified proteins.

and transcription activation. Examples of this scenario have been reported in diabetic kidney models (Cai et al., 2005). Changes in the $2 \mathrm{GSH} / \mathrm{GSSG}$ ratio may induce S-glutathionylation of the $\mathrm{p} 50$ subunit of $\mathrm{NF \kappa B}$ at the cysteine 62 residue (Pineda-Molina et al., 2001). Further to this, the sulfenation of this same residue was also described. As for p65, S-glutathionylation has been reported (Qanungo et al., 2007; Lin et al., 2012). However there is a lack of direct evidence for the occurrence of this modification in diabetic models.

Ras is involved in insulin-induced PI3K signaling, even when its role is not essential (van den Berghe et al., 1994). Ras glutathionylation has been described in models such as vascular smooth muscle cells and cardiomyocytes after exposure to angiotensin II and mechanical strain (Adachi et al., 2004; Pimentel et al., 2006). The modification takes place at cysteine 118 and, interestingly, it represents a gain of function. Related to this signaling cascade is the mitogen activated protein kinase (MAPK)/ extracellular signal-regulated kinase (ERK) kinase (MEKK) that mediates Ras-Raf signal transduction to c-Jun $\mathrm{NH}_{2}$-terminal kinase (JNK) and c-Jun (Vojtek and Der, 1998). MEKK1 is inhibited by S-glutathionylation in menadione-treated lymph node carcinoma cells (Cross and Templeton, 2004) and overexpression of Grx in HEK293 cells increases the MEKK-mediated activation of NFKB (Hirota et al., 2000).
Downstream of MEKK is JNK and c-Jun. The latter has been reported to be sensitive to variations in 2GSH/GSSG ratio (Wilhelm et al., 1997). In in vitro experiments, treatments with physiological concentrations of GSH plus DEA-NO, a NO donor, or GSSG, induced the glutathionylation of c-Jun (Klatt et al., 1999a,b).

As mentioned above, some of the proteins that have been identified as suffering thiolation in signaling related to diabetic pathways are also modified in other diseases, stressing the importance of this posttranslational modification. Insulin-degrading enzyme (IDE) hydrolyzes a number of small peptides. IDE is inhibited by thiolreactive agents that directly target cysteine residues (Neant-Fery et al., 2008). The insulin degradation activity of purified IDE is inhibited by the addition of GSSG, dithiothreitol being partially able to recover this activity. It has consistently been shown that GSSG treatment induces S-glutathionylation of the recombinant protein (Cordes et al., 2011), representing a potential pathway by which unbalances in oxidative state may alter the response to insulin in diabetes. The oxidative modifications of redox-sensitive proteins are acquiring relevance in human disorders. Tyrosine and dual phosphatases contain a highly-sensitive cysteine residue that is critical for their catalytic activity. Recently, mitogen-activated protein kinase phosphatase 1 (MKP-1) has been described 
to be S-glutathionylated in primed monocytes, with subsequent inactivation of its function (Kim et al., 2012b) as this modification renders MKP-1 susceptible to degradation by the proteasome. In this report, chronic exposure of human THP-1 monocytes to diabetic milieu resulted in the loss of MKP-1 protein levels, hyperactivation of ERK and p38 MAPK and increased monocyte adhesion and chemotaxis. However, overexpression of Grx1 protected MKP-1 from degradation. Monocytes from diabetic mice presented reduced levels of MKP-1 protein. Overall, current evidence supports the role of oxidative modifications of redox-sensitive proteins in the development of diseases related to the overproduction of ROS.

\section{Diabetic animal models and S-glutathionylation}

In order to confirm the in vivo role of S-thiolation in diabetes, animal models testing the expression and function of antioxidant enzymes involved in the reversibility of S-glutathionylation have been used. In diabetic retinae, Grx1 proteins levels are increased compared to non-diabetic controls. In retinal cells treated with high glucose, the same effects were observed, accompanied by nuclear translocation of $\mathrm{NF} \kappa \mathrm{B}$ components and an increase in the reporter activity of NFKB-regulated promoter constructs. This finally resulted in increased expression of intercellular adhesion molecule, a classic inflammatory molecule involved in diabetic complications. In addition, overexpression or repression of Grx1 by genetic means confirmed the role of Grx1 in the diabetic retinopathy model (Shelton et al., 2007). More recently, the site of regulation was located in the cytoplasm, where the IKK $\beta$ subunit was identified as S-glutathionylated and suggested to be responsible for Grx1-induced intercellular adhesion molecule overexpression (Shelton et al., 2009). Other proinflammatory effects related to Grx1 S-glutathionylation have been reported. Neutrophils play a key role in inflammation processes, such as those related to diabetic nephropathy (Galkina and Ley, 2006), adipose tissue inflammation and diabetic retinopathy (Kim et al., 2005). Neutrophils from diabetic patients have decreased phagocytic activity, impaired bacterial killing and significantly more superoxide generation compared to control neutrophils. In diabetic mice, neutrophil apoptosis and clearance by macrophages become reduced and this led to prolonged production of tumor necrosis factor $\alpha$ (TNF- $\alpha$ ), which might contribute to chronic inflammation (Hanses et al., 2011).
Recent studies have identified different polymorphonuclear proteins, which undergo S-glutathionylation under oxidative stress conditions. S-glutathionylation of S100A9 regulates its inflammatory activity in neutrophils (Lim et al., 2010). In another study, it was found that increased levels of $\mathrm{H}_{2} \mathrm{O}_{2}$ results in diminished proteasomal activity of $26 \mathrm{~S}$ proteasome via S-glutathionylation of its regulatory subunit Rpn2 (Zmijewski et al., 2009). A recent report describes how stimulated neutrophils present deglutathionylated actin and associated polymerization, neutrophil polarization, chemotaxis, adhesion and phagocytosis. When Grx1 expression was silenced in cells or ablated in a murine model, actin was S-glutathionylated, neutrophil recruitment to sites of inflammation was impaired, and the bactericidal capability was reduced (Sakai et al., 2012). All these reports highlight the role of protein-S-glutathionylation in the alteration of neutrophil function and might be responsible for neutrophil dysfunction in diabetic disease.

In the course of diabetes, endothelial dysfunction is an early event favoring the development of vascular complications (Jay et al., 2006). The latter have been associated with endothelial dysfunction and vascular superoxide production attributed to NOX activation contributing to the uncoupling of eNOS (Hink et al., 2001). Uncoupled eNOS itself may lead to increased superoxide generation, thus establishing a vicious cycle. The accepted traditional mechanism leading to eNOS uncoupling is related to diminished levels of $\mathrm{BH}_{4}$, an essential cofactor for its catalytic activity. Interestingly, the S-glutathionylation of eNOS in vitro has recently been reported (Chen et al., 2011). $\mathrm{BH}_{4}$ is able to increase S-glutathionylation due to a reduction in the 2GSH/GSSG ratio (Crabtree et al., 2013). Also in vivo experiments have described the presence of S-glutathionylation in aortic homogenates of diabetic rats (Schuhmacher et al., 2011). This evidence has added a new angle to the problem. This modification was dependent on NOX1 and NOX2 activation and was prevented by a novel NO donor that does not induce nitrate resistance in these animals. It has been suggested that S-thiolation of eNOS may potentially contribute to the temporal protection of the protein from over-oxidation. These studies further emphasize the involvement of S-glutathionylation in the pathophysiological responses underlying diabetic complications both in vitro and in vivo.

\section{S-glutathionylation in diabetic patients}

As already mentioned, there is considerable evidence supporting the fact that high levels of oxidative stress and 
down-regulation of antioxidant defenses underlie diabetic complications in experimental models. For this reason studies, in human samples attempting to corroborate the importance of S-glutathionylation in diabetes have been undertaken. A major caveat here is that the alterations observed in experimental models are related to tissues that are not easily available in patients. As expected, studies of blood samples are the most commonly reported regarding the study of oxidative changes. Early reports described that glutathione metabolism was impaired in erythrocytes from patients with diabetes mellitus (Murakami et al., 1989). Decreased levels of GSH and increased levels of GSSG were found. The activity of GCL, GR and the rate of outward transport of GSSG were decreased in diabetic patients, suggesting impaired synthesis of GSH and GSSG detoxification function. This impairment has been correlated with increased blood accumulation of sorbitol, an end-product of the polyol pathway, which is up-regulated in diabetes (Ciuchi et al., 1996). The decrease in antioxidant defenses further worsens when diabetes becomes chronic. Significant differences have been reported in plasma $\alpha$-tocopherol, plasma selenium, average antioxidant levels and GPxs in erythrocytes and plasma (Whiting et al., 2008). In non-chronic hyperglycemic patients, the differences in several oxidation parameters in healthy patients were smaller or absent compared to chronic diabetic patients, suggesting that chronicity is one factor that contributes to the pro-oxidative state. The depletion of GSH in erythrocytes could be due to decreased synthesis, increased utilization, or the combination of both. In poorly-controlled adolescent patients with diabetes, the synthesis of GSH was studied by using radiolabeled cysteine detection in erythrocytes (Darmaun et al., 2005). There was a significant decrease in GSH levels, but not in the absolute synthesis rate, suggesting that glutathione depletion arises from increased utilization. The supplementation of these patients with $N$-acetylcysteine failed to raise erythrocyte cysteine or GSH concentrations and did not alter erythrocyte GSH synthesis rate (Darmaun et al., 2008).

S-glutathionylation has also been explored in the blood samples of diabetic patients to verify whether this modification correlates with the degree of diabetic complications. For instance, S-glutathionylation of hemoglobin was studied by liquid chromatography-electrospray ionization-mass spectrometry in blood samples from hemodialysis patients, showing increased levels in the hemolysates of diabetic patients, an observation that positively correlated with higher plasma malondialdehyde and creatinine levels (Naito et al., 1999). Levels of S-glutathionylated hemoglobin in diabetic patients were reduced by the administration of tocopherol nicotinate (vitamin-E) during the eight days before the sample extraction. This suggested that by increasing the antioxidant levels in blood, S-glutathionylated hemoglobin could be reduced (Naito and Niwa, 2000). S-thiolation of hemoglobin was also increased in hyperlipidemic patients, suggesting that it may represent a clinical marker of oxidative stress (Niwa et al., 2000). The downsides of the potential diagnostic use of this modification are the facts that the liquid chromatography-electrospray ionization-mass spectrometry technique is not widely available and that GSSG and protein-SG may be formed due to excessive oxygenation of blood samples (Giustarini et al., 2003). To circumvent these limitations, high-performance liquid chromatography coupled to fluorescent detection, but this approach requires long and thorough manipulation. The presence of microangiopathic complications, such as those of diabetic retinopathy and nephropathy, positively correlate with the presence of S-glutathionylated hemoglobin in diabetic patients, increasing the prevalence of this modification in diabetic patients without microangiopathy (Sampathkumar et al., 2005). Modified hemoglobin also positively correlated with duration of diabetes, $\mathrm{HbA}_{1 \mathrm{c}}$ (glycated hemoglobin) and thiobarbituric acid reactive substances (TBARS) levels, and negatively correlated with GSH levels. Consideration of such evidence suggests that S-glutathionylated hemoglobin could be a clinical biomarker of oxidative stress and altered redox regulation in diabetes and its microangiopathy. However, a more recent report proposes that modified hemoglobin is not increased in diabetes and is not related to hyperglycemia or oxidative stress markers (Hoffmann et al., 2008). Therefore, extensive effort should be made to study this modification in blood in order to determine whether S-glutathionylation could represent a diabetic biomarker, and to identify other modified proteins with a potential therapeutic role.

\section{Perspectives}

Current analysis of the literature supports the relevance of S-glutathionylation in diseases that involve with oxidative stress. Diabetes in particular is one of the most prevalent diseases in the world and all prediction models point to a future increase in the total number of diabetic patients. Early detection and control of hyperglycemia are critical milestones in the treatment of the disease. Moreover evidence has been reported for high oxidative stress markers in erythrocytes from diabetic adolescent patients (Darmaun et al., 2005, 2008). These patients, although 
with a short diabetic history, already has alterations in one of the parameters that increase cardiovascular risk. Therefore, the development of early diagnostic biomarkers appears to be critical.

Taking into account the clear induction of S-glutathionylation in proteins related to diabetic conditions, it seems reasonable that the identification and characterization of modified proteins in diabetic models and patients should become an important aim as it may help to prevent diabetic complications. This notion is underscored by the need for early tight control that should be adopted to avoid 'hyperglycemic memory' (Giacco and Brownlee, 2010). According to this concept, epigenetic changes, such as posttranslational modifications of histones induced in singular early hyperglycemic events, could lead to the development of pathological complications, even when intensive glycemic control has been achieved.

Finally, blood samples represent a good source from which to identify potential S-glutathionylated proteins as biomarkers, inasmuch as the generation of these samples continues to be the least invasive method. Unpublished data from our laboratory provide evidence for increased levels of S-glutathionylation present in primary neutrophils isolated from 16-week-old diabetic $d b / d b$ mice. The increased levels of S-glutathionylation compared with lean mice support the relevance of this modification, and the potential use of these samples for the detection of new biomarkers and potentially new targets. Important challenges lie ahead not only related to the identification of these biomarkers in blood cells, but also related to the development of fast and cost-effective methods for their detection, especially when the expected size of the diabetic population will continue to increase in both postindustrial societies and overpopulated countries with emerging economies (Wild et al., 2004; Yoon et al., 2006).

Acknowledgments: This work was supported by grants from the Spanish Ministerio de Economía y Competitividad (MINECO) SAF 2009-07520, CSD-2007-00020, SAF 2012-31338, from the Comunidad Autónoma de Madrid S2010-BMD2321, from the Consejo Superior de Investigaciones Científicas PIE201020E06 and the 'New Indigo' Partnership Program 'Nitroxdiab' (PIM2010ENI-00631). The CBMSO lab receives support from Fundación Renal 'Iñigo Alvarez de Toledo' and the CBMSO institutional support from 'Fundación Ramón Areces'.

Received March 19, 2013; accepted June 10, 2013; previously published online June 12, 2013

\section{References}

Adachi, T., Pimentel, D.R., Heibeck, T., Hou, X., Lee, Y.J., Jiang, B., Ido, Y., and Cohen, R.A. (2004). S-glutathiolation of Ras mediates redox-sensitive signaling by angiotensin II in vascular smooth muscle cells. J. Biol. Chem. 279, 29857-29862.

Akerboom, T.P., Bilzer, M., and Sies, H. (1982). Competition between transport of glutathione disulfide (GSSG) and glutathione S-conjugates from perfused rat liver into bile. FEBS Lett. 140, 73-76.

Alisi, A., Bruscalupi, G., Pastore, A., Petrini, S., Panera, N., Massimi, M., Tozzi, G., Leoni, S., Piemonte, F., and Nobili, V. (2012). Redox homeostasis and posttranslational modifications/activity of phosphatase and tensin homolog in hepatocytes from rats with diet-induced hepatosteatosis. J. Nutr. Biochem. 23, 169-178.

Alp, N.J. and Channon, K.M. (2004). Regulation of endothelial nitric oxide synthase by tetrahydrobiopterin in vascular disease. Arterioscler. Thromb. Vasc. Biol. 24, 413-420.

Arkan, M.C., Hevener, A.L., Greten, F.R., Maeda, S., Li, Z.W., Long, J.M., Wynshaw-Boris, A., Poli, G., Olefsky, J., and Karin, M. (2005). IKK- $\beta$ links inflammation to obesity-induced insulin resistance. Nat. Med. 11, 191-198.

Banning, A. and Brigelius-Flohe, R. (2005). NF- $\mathrm{kB}$, Nrf2, and HO-1 interplay in redox-regulated VCAM-1 expression. Antioxid. Redox Signal. 7, 889-899.
Barrett, W.C., DeGnore, J.P., Konig, S., Fales, H.M., Keng, Y.F., Zhang, Z.Y., Yim, M.B., and Chock, P.B. (1999). Regulation of PTP1B via glutathionylation of the active site cysteine 215. Biochemistry 38, 6699-6705.

Bartling, D., Radzio, R., Steiner, U., and Weiler, E.W. (1993). A glutathione S-transferase with glutathione-peroxidase activity from Arabidopsis thaliana. Molecular cloning and functional characterization. Eur. J. Biochem. 216, 579-586.

Benassi, B., Fanciulli, M., Fiorentino, F., Porrello, A., Chiorino, G., Loda, M., Zupi, G., and Biroccio, A. (2006). c-Myc phosphorylation is required for cellular response to oxidative stress. Mol. Cell. 21, 509-519.

Board, P.G., Coggan, M., Chelvanayagam, G., Easteal, S., Jermiin, L.S., Schulte, G.K., Danley, D.E., Hoth, L.R., Griffor, M.C., Kamath, A.V., et al. (2000). Identification, characterization, and crystal structure of the Omega class glutathione transferases. J. Biol. Chem. 275, 24798-24806.

Boveris, A. (1977). Mitochondrial production of superoxide radical and hydrogen peroxide. Adv. Exp. Med. Biol. 78, 67-82.

Brigelius-Flohe, R. (2006). Glutathione peroxidases and redoxregulated transcription factors. Biol. Chem. 387, 1329-1335.

Cai, D., Yuan, M., Frantz, D.F., Melendez, P.A., Hansen, L., Lee, J., and Shoelson, S.E. (2005). Local and systemic insulin resistance resulting from hepatic activation of IKK-beta and NF- B. Nat. Med. 11, 183-190. 
Chen, C.A., Wang, T.Y., Varadharaj, S., Reyes, L.A., Hemann, C., Talukder, M.A., Chen, Y.R., Druhan, L.J., and Zweier, J.L. (2011). S-glutathionylation uncouples eNOS and regulates its cellular and vascular function. Nature 468, 1115-1118.

Cheng, J., Cui, R., Chen, C.H., and Du, J. (2007). Oxidized low-density lipoprotein stimulates p53-dependent activation of proapoptotic Bax leading to apoptosis of differentiated endothelial progenitor cells. Endocrinology 148, 2085-2094.

Cho, H.Y., Reddy, S.P., Debiase, A., Yamamoto, M., and Kleeberger, S.R. (2005). Gene expression profiling of NRF2-mediated protection against oxidative injury. Free Radic. Biol. Med. 38, 325-343.

Ciuchi, E., Odetti, P., and Prando, R. (1996). Relationship between glutathione and sorbitol concentrations in erythrocytes from diabetic patients. Metabolism 45, 611-613.

Coleman, J., Blake-Kalff, M., and Davies, E. (1997). Detoxification of xenobiotics by plants: chemical modification and vacuolar compartmentation. Trends Plant. Sci. 2, 144-151.

Cordes, C.M., Bennett, R.G., Siford, G.L., and Hamel, F.G. (2011). Redox regulation of insulin degradation by insulin-degrading enzyme. PLoS One 6, e18138.

Crabtree, M.J., Brixey, R., Batchelor, H., Hale, A.B., and Channon, K.M. (2013). Integrated redox sensor and effector functions for tetrahydrobiopterin- and glutathionylation-dependent endothelial nitric-oxide synthase uncoupling. J. Biol. Chem. 288, 561-569.

Craven, P.A., Studer, R.K., and DeRubertis, F.R. (1994). Impaired nitric oxide-dependent cyclic guanosine monophosphate generation in glomeruli from diabetic rats. Evidence for protein kinase C-mediated suppression of the cholinergic response. J. Clin. Invest. 93, 311-320.

Cross, J.V. and Templeton, D.J. (2004). Oxidative stress inhibits MEKK1 by site-specific glutathionylation in the ATP-binding domain. Biochem. J. 381, 675-683.

Dalle-Donne, I., Milzani, A., Gagliano, N., Colombo, R., Giustarini, D., and Rossi, R. (2008). Molecular mechanisms and potential clinical significance of S-glutathionylation. Antioxid. Redox Signal. 10, 445-473.

Darmaun, D., Smith, S.D., Sweeten, S., Sager, B.K., Welch, S., and Mauras, N. (2005). Evidence for accelerated rates of glutathione utilization and glutathione depletion in adolescents with poorly controlled type 1 diabetes. Diabetes 54, 190-196.

Darmaun, D., Smith, S.D., Sweeten, S., Hartman, B.K., Welch, S., and Mauras, N. (2008). Poorly controlled type 1 diabetes is associated with altered glutathione homeostasis in adolescents: apparent resistance to $\mathrm{N}$-acetylcysteine supplementation. Pediatr. Diabetes 9, 577-582.

Dasgupta, A., Das, S., and Sarkar, P.K. (2007). Thyroid hormone promotes glutathione synthesis in astrocytes by up regulation of glutamate cysteine ligase through differential stimulation of its catalytic and modulator subunit mRNAs. Free Radic. Biol. Med. 42, 617-626.

Duh, E.J., Yang, H.S., Suzuma, I., Miyagi, M., Youngman, E., Mori, K., Katai, M., Yan, L., Suzuma, K., West, K., et al. (2002). Pigment epithelium-derived factor suppresses ischemia-induced retinal neovascularization and VEGF-induced migration and growth. Invest. Ophthalmol. Vis. Sci. 43, 821-829.

Flohe, L., Gunzler, W.A., and Schock, H.H. (1973). Glutathione peroxidase: a selenoenzyme. FEBS Lett. 32, 132-134.
Forman, H.J., Maiorino, M., and Ursini, F. (2010). Signaling functions of reactive oxygen species. Biochemistry 49, 835-842.

Franklin, C.C., Krejsa, C.M., Pierce, R.H., White, C.C., Fausto, N., and Kavanagh, T.J. (2002). Caspase-3-dependent cleavage of the glutamate-L-cysteine ligase catalytic subunit during apoptotic cell death. Am. J. Pathol. 160, 1887-1894.

Frischer, H. and Ahmad, T. (1977). Severe generalized glutathione reductase deficiency after antitumor chemotherapy with BCNU [1,3-bis(chloroethyl)-1-nitrosourea]. J. Lab. Clin. Med. 89, 1080-1091.

Galkina, E. and Ley, K. (2006). Leukocyte recruitment and vascular injury in diabetic nephropathy. J. Am. Soc. Nephrol. 17, 368-377.

Gallwitz, H., Bonse, S., Martinez-Cruz, A., Schlichting, I., Schumacher, K., and Krauth-Siegel, R.L. (1999). Ajoene is an inhibitor and subversive substrate of human glutathione reductase and Trypanosoma cruzi trypanothione reductase: crystallographic, kinetic, and spectroscopic studies. J. Med. Chem. 42, 364-372.

Galperin, M.Y. and Koonin, E.V. (1997). A diverse superfamily of enzymes with ATP-dependent carboxylate-amine/thiol ligase activity. Protein Sci. 6, 2639-2643.

Garcia-Ruiz, C. and Fernandez-Checa, J.C. (2006). Mitochondrial glutathione: hepatocellular survival-death switch. J. Gastroenterol. Hepatol. 21 (Suppl 3), S3-S6.

Giacco, F. and Brownlee, M. (2010). Oxidative stress and diabetic complications. Circ. Res. 107, 1058-1070.

Ginnan, R., Guikema, B.J., Halligan, K.E., Singer, H.A., and Jourd'heuil, D. (2008). Regulation of smooth muscle by inducible nitric oxide synthase and NADPH oxidase in vascular proliferative diseases. Free Radic. Biol. Med. 44, 1232-1245.

Giustarini, D., Dalle-Donne, I., Colombo, R., Petralia, S., Giampaoletti, S., Milzani, A., and Rossi, R. (2003). Protein glutathionylation in erythrocytes. Clin. Chem. 49, 327-330.

Goldstein, B.J. (2001). Protein-tyrosine phosphatase 1B (PTP1B): a novel therapeutic target for type 2 diabetes mellitus, obesity and related states of insulin resistance. Curr. Drug Targets Immune. Endocr. Metabol. Disord. 1, 265-275.

Goldstein, B.J., Mahadev, K., and Wu, X. (2005). Redox paradox: insulin action is facilitated by insulin-stimulated reactive oxygen species with multiple potential signaling targets. Diabetes 54, 311-321.

Griffith, O.W. and Meister, A. (1980). Excretion of cysteine and gamma-glutamylcysteine moieties in human and experimental animal $\gamma$-glutamyl transpeptidase deficiency. Proc. Natl. Acad. Sci. USA 77, 3384-3387.

Hanigan, M.H. (1998). $\gamma$-Glutamyl transpeptidase, a glutathionase: its expression and function in carcinogenesis. Chem. Biol. Interact. 111-112, 333-342.

Hanses, F., Park, S., Rich, J., and Lee, J.C. (2011). Reduced neutrophil apoptosis in diabetic mice during staphylococcal infection leads to prolonged TNF $\alpha$ production and reduced neutrophil clearance. PLoS One 6, e23633.

Harvey, C.J., Thimmulappa, R.K., Singh, A., Blake, D.J., Ling, G., Wakabayashi, N., Fujii, J., Myers, A., and Biswal, S. (2009). Nrf2-regulated glutathione recycling independent of biosynthesis is critical for cell survival during oxidative stress. Free Radic. Biol. Med. 46, 443-453.

Hayes, J.D., Flanagan, J.U., and Jowsey, I.R. (2005). Glutathione transferases. Annu. Rev. Pharmacol. Toxicol. 45, 51-88. 
Hink, U., Li, H., Mollnau, H., Oelze, M., Matheis, E., Hartmann, M., Skatchkov, M., Thaiss, F., Stahl, R.A., Warnholtz, A., et al. (2001). Mechanisms underlying endothelial dysfunction in diabetes mellitus. Circ. Res. 88, E14-E22.

Hirota, K., Matsui, M., Murata, M., Takashima, Y., Cheng, F.S., Itoh, T., Fukuda, K., and Yodoi, J. (2000). Nucleoredoxin, glutaredoxin, and thioredoxin differentially regulate $\mathrm{NF}-\mathrm{\kappa B}$, AP-1, and CREB activation in HEK293 cells. Biochem. Biophys. Res. Commun. 274, 177-182.

Hodge, J.E. (1955). The Amadori rearrangement. Adv. Carbohydr. Chem. 10, 169-205.

Hoffmann, P., Woon, J., Rowley, K.G., Karschimkus, C., Nelson, C.L., Dragicevic, G., O'Neal, D., Wilson, A., Croft, K.D., Mori, T.A., et al. (2008). Glutathionyl haemoglobin is not increased in diabetes nor related to glycaemia, complications, dyslipidaemia, inflammation or other measures of oxidative stress. Diabetes Res. Clin. Pract. 80, e1-e3.

Holmgren, A. (1976). Hydrogen donor system for Escherichia coli. ribonucleoside-diphosphate reductase dependent upon glutathione. Proc. Natl. Acad. Sci. USA 73, 2275-2279.

Hong, J.H., Kim, M.J., Park, M.R., Kwag, O.G., Lee, I.S., Byun, B.H., Lee, S.C., Lee, K.B., and Rhee, S.J. (2004). Effects of vitamin $E$ on oxidative stress and membrane fluidity in brain of streptozotocin-induced diabetic rats. Clin. Chim. Acta 340, 107-115.

Huang, C.S., Chang, L.S., Anderson, M.E., and Meister, A. (1993). Catalytic and regulatory properties of the heavy subunit of rat kidney $\gamma$-glutamylcysteine synthetase. J. Biol. Chem. 268, 19675-19680.

Inoguchi, T., Sonta, T., Tsubouchi, H., Etoh, T., Kakimoto, M., Sonoda, N., Sato, N., Sekiguchi, N., Kobayashi, K., Sumimoto, H., et al. (2003). Protein kinase C-dependent increase in reactive oxygen species (ROS) production in vascular tissues of diabetes: role of vascular NAD(P)H oxidase. J. Am. Soc. Nephrol. 14, S227-S232.

Jakobsson, P.J., Thoren, S., Morgenstern, R., and Samuelsson, B. (1999). Identification of human prostaglandin E synthase: a microsomal, glutathione-dependent, inducible enzyme, constituting a potential novel drug target. Proc. Natl. Acad. Sci. USA 96, 7220-7225.

Jardine, H., MacNee, W., Donaldson, K., and Rahman, I. (2002). Molecular mechanism of transforming growth factor (TGF)- $\beta 1$ induced glutathione depletion in alveolar epithelial cells. Involvement of AP-1/ARE and Fra-1. J. Biol. Chem. 277, 21158-21166.

Jay, D., Hitomi, H., and Griendling, K.K. (2006). Oxidative stress and diabetic cardiovascular complications. Free Radic. Biol. Med. 40, 183-192.

Jean, J.C., Liu, Y., Brown, L.A., Marc, R.E., Klings, E., and Joyce-Brady, M. (2002). Gamma-glutamyl transferase deficiency results in lung oxidant stress in normoxia. Am. J. Physiol. Lung Cell. Mol. Physiol. 283, L766-L776.

Kanwar, Y.S., Wada, J., Sun, L., Xie, P., Wallner, E.I., Chen, S., Chugh, S., and Danesh, F.R. (2008). Diabetic nephropathy: mechanisms of renal disease progression. Exp. Biol. Med. (Maywood) 233, 4-11.

Kaplowitz, N., Aw, T.Y., and Ookhtens, M. (1985). The regulation of hepatic glutathione. Annu. Rev. Pharmacol. Toxicol. 25, 715-744.

Kim, S.K., Woodcroft, K.J., Khodadadeh, S.S., and Novak, R.F. (2004). Insulin signaling regulates $\gamma$-glutamylcysteine ligase catalytic subunit expression in primary cultured rat hepatocytes. J. Pharmacol. Exp. Ther. 311, 99-108.
Kim, S.Y., Johnson, M.A., McLeod, D.S., Alexander, T., Hansen, B.C., and Lutty, G.A. (2005). Neutrophils are associated with capillary closure in spontaneously diabetic monkey retinas. Diabetes 54, 1534-1542.

Kim, K., Kim, S.H., Kim, J., Kim, H., and Yim, J. (2012a). Glutathione s-transferase omega 1 activity is sufficient to suppress neurodegeneration in a Drosophila model of Parkinson disease. J. Biol. Chem. 287, 6628-6641.

Kim, H.S., Ullevig, S.L., Zamora, D., Lee, C.F., and Asmis, R. (2012b). Redox regulation of MAPK phosphatase 1 controls monocyte migration and macrophage recruitment. Proc. Natl. Acad. Sci. USA 109, E2803-E2812.

Klatt, P. and Lamas, S. (2000). Regulation of protein function by S-glutathiolation in response to oxidative and nitrosative stress. Eur. J. Biochem. 267, 4928-4944.

Klatt, P., Molina, E.P., De Lacoba, M.G., Padilla, C.A., MartinezGalesteo, E., Barcena, J.A., and Lamas, S. (1999a). Redox regulation of c-Jun DNA binding by reversible S-glutathiolation. FASEB J. 13, 1481-1490.

Klatt, P., Molina, E.P., and Lamas, S. (1999b). Nitric oxide inhibits c-Jun DNA binding by specifically targeted S-glutathionylation. J. Biol. Chem. 274, 15857-15864.

Koo, J.R. and Vaziri, N.D. (2003). Effects of diabetes, insulin and antioxidants on NO synthase abundance and NO interaction with reactive oxygen species. Kidney Int. 63, 195-201.

Kovacic, P. and Somanathan, R. (2011). Cell signaling and receptors in toxicity of advanced glycation end products (AGEs): $\alpha$-dicarbonyls, radicals, oxidative stress and antioxidants. J. Recept. Signal. Tr. R. 31, 332-339.

Lee, T.D., Yang, H., Whang, J., and Lu, S.C. (2005). Cloning and characterization of the human glutathione synthetase 5'-flanking region. Biochem. J. 390, 521-528.

Lieberman, M.W., Wiseman, A.L., Shi, Z.Z., Carter, B.Z., Barrios, R., Ou, C.N., Chevez-Barrios, P., Wang, Y., Habib, G.M., Goodman, J.C., et al. (1996). Growth retardation and cysteine deficiency in $\gamma$-glutamyl transpeptidase-deficient mice. Proc. Natl. Acad. Sci. USA 93, 7923-7926.

Lillig, C.H., Berndt, C., and Holmgren, A. (2008). Glutaredoxin systems. Biochim. Biophys. Acta. 1780, 1304-1317.

Lim, S.Y., Raftery, M.J., Goyette, J., and Geczy, C.L. (2010). S-glutathionylation regulates inflammatory activities of S100A9. J. Biol. Chem. 285, 14377-14388.

Lin, Y.M., Furukawa, Y., Tsunoda, T., Yue, C.T., Yang, K.C., and Nakamura, Y. (2002). Molecular diagnosis of colorectal tumors by expression profiles of 50 genes expressed differentially in adenomas and carcinomas. Oncogene 21, 4120-4128.

Lin, Y.C., Huang, G.D., Hsieh, C.W., and Wung, B.S. (2012). The glutathionylation of $\mathrm{p} 65$ modulates NF-kappaB activity in 15-deoxy-Delta(1)(2),(1)(4)-prostaglandin J(2)-treated endothelial cells. Free Radic. Biol. Med. 52, 1844-1853.

Little, C. and O'Brien, P.J. (1968). An intracellular GSH-peroxidase with a lipid peroxide substrate. Biochem. Biophys. Res. Commun. 31, 145-150.

Loh, K., Deng, H., Fukushima, A., Cai, X., Boivin, B., Galic, S., Bruce, C., Shields, B.J., Skiba, B., Ooms, L.M., et al. (2009). Reactive oxygen species enhance insulin sensitivity. Cell. Metab. 10, 260-272.

Lu, M.P., Wang, R., Song, X., Wang, X., Wu, L., and Meng, Q.H. (2008). Modulation of methylglyoxal and glutathione by 
soybean isoflavones in mild streptozotocin-induced diabetic rats. Nutr. Metab. Cardiovasc. Dis. 18, 618-623.

Lu, S.C. (1999). Regulation of hepatic glutathione synthesis: current concepts and controversies. FASEB J. 13, 1169-1183.

Lu, S.C., Ge, J.L., Kuhlenkamp, J., and Kaplowitz, N. (1992). Insulin and glucocorticoid dependence of hepatic $\gamma$-glutamylcysteine synthetase and glutathione synthesis in the rat. Studies in cultured hepatocytes and in vivo. J. Clin. Invest. 90, 524-532.

Luo, J.L., Hammarqvist, F., Andersson, K., and Wernerman, J. (1998). Surgical trauma decreases glutathione synthetic capacity in human skeletal muscle tissue. Am. J. Physiol. 275, E359-E365.

MacDonald, M.J., Chaplen, F.W., Triplett, C.K., Gong, Q., and Drought, H. (2006). Stimulation of insulin release by glyceraldehyde may not be similar to glucose. Arch. Biochem. Biophys. 447, 118-126.

Manevich, Y., Feinstein, S.I., and Fisher, A.B. (2004). Activation of the antioxidant enzyme 1-CYS peroxiredoxin requires glutathionylation mediated by heterodimerization with pi GST. Proc. Natl. Acad. Sci. USA 101, 3780-3785.

Mannervik, B. and Axelsson, K. (1975). Reduction of disulphide bonds in proteins mixed disulphides catalysed by a thioltransferase in rat liver cytosol. Biochem. J. 149, 785-788.

Martin, D.D., Vilas, G.L., Prescher, J.A., Rajaiah, G., Falck, J.R., Bertozzi, C.R., and Berthiaume, L.G. (2008). Rapid detection, discovery, and identification of post-translationally myristoylated proteins during apoptosis using a bio-orthogonal azidomyristate analog. FASEB J. 22, 797-806.

Martinez-Ruiz, A. and Lamas, S. (2005). Nitrosylation of thiols in vascular homeostasis and disease. Curr. Atheroscler. Rep. 7, 213-218.

Martinez-Ruiz, A. and Lamas, S. (2007). Signalling by NO-induced protein S-nitrosylation and S-glutathionylation: convergences and divergences. Cardiovasc. Res. 75, 220-228.

Mastrocola, R., Restivo, F., Vercellinatto, I., Danni, O., Brignardello, E., Aragno, M., and Boccuzzi, G. (2005). Oxidative and nitrosative stress in brain mitochondria of diabetic rats. J. Endocrinol. 187, 37-44.

Matoba, T., Shimokawa, H., Kubota, H., Morikawa, K., Fujiki, T., Kunihiro, I., Mukai, Y., Hirakawa, Y., and Takeshita, A. (2002). Hydrogen peroxide is an endothelium-derived hyperpolarizing factor in human mesenteric arteries. Biochem. Biophys. Res. Commun. 290, 909-913.

McClung, J.P., Roneker, C.A., Mu, W., Lisk, D.J., Langlais, P., Liu, F., and Lei, X.G. (2004). Development of insulin resistance and obesity in mice overexpressing cellular glutathione peroxidase. Proc. Natl. Acad. Sci. USA 101, 8852-8857.

Mcllwain, C.C., Townsend, D.M., and Tew, K.D. (2006). Glutathione S-transferase polymorphisms: cancer incidence and therapy. Oncogene 25, 1639-1648.

Meister, A. (1974). The $\gamma$-glutamyl cycle. Diseases associated with specific enzyme deficiencies. Ann. Intern. Med. 81, 247-253.

Meister, A. (1988). Glutathione metabolism and its selective modification. J. Biol. Chem. 263, 17205-17208.

Meister, A. and Anderson, M.E. (1983). Glutathione. Annu. Rev. Biochem. 52, 711-760.

Mieyal, J.J., Gallogly, M.M., Qanungo, S., Sabens, E.A., and Shelton, M.D. (2008). Molecular mechanisms and clinical implications of reversible protein S-glutathionylation. Antioxid. Redox Signal. 10, 1941-1988.
Mills, G.C. (1957). Hemoglobin catabolism. I. Glutathione peroxidase, an erythrocyte enzyme which protects hemoglobin from oxidative breakdown. J. Biol. Chem. 229, 189-197.

Morgan, B., Ezerina, D., Amoako, T.N., Riemer, J., Seedorf, M., and Dick, T.P. (2013). Multiple glutathione disulfide removal pathways mediate cytosolic redox homeostasis. Nat. Chem. Biol. 9, 119-125.

Morocutti, A., Sethi, M., Hayward, A., Lee, A., and Viberti, G. (1998). Glutathione reverses the growth abnormalities of skin fibroblasts from insulin-dependent diabetic patients with nephropathy. J. Am. Soc. Nephrol. 9, 1060-1066.

Murakami, K., Kondo, T., Ohtsuka, Y., Fujiwara, Y., Shimada, M., and Kawakami, Y. (1989). Impairment of glutathione metabolism in erythrocytes from patients with diabetes mellitus. Metabolism 38, 753-758.

Murata, H., Ihara, Y., Nakamura, H., Yodoi, J., Sumikawa, K., and Kondo, T. (2003). Glutaredoxin exerts an antiapoptotic effect by regulating the redox state of Akt. J. Biol. Chem. 278, 50226-50233.

Naito, C. and Niwa, T. (2000). Analysis of glutathionyl hemoglobin levels in diabetic patients by electrospray ionization liquid chromatography-mass spectrometry: effect of vitamin $E$ administration. J. Chromatogr. B Biomed. Sci. Appl. 746, 91-94.

Naito, C., Kajita, M., and Niwa, T. (1999). Determination of glutathionyl hemoglobin in hemodialysis patients using electrospray ionization liquid chromatography-mass spectrometry. J. Chromatogr. B Biomed. Sci. Appl. 731, 121-124.

Namiki, M., Hayashi, T., and Ohta, Y. (1977). Novel free radicals formed by the amino-carbonyl reactions of sugars with amino acids, amines, and proteins. Adv. Exp. Med. Biol. 86B, 471-501.

Neant-Fery, M., Garcia-Ordonez, R.D., Logan, T.P., Selkoe, D.J., Li, L., Reinstatler, L., and Leissring, M.A. (2008). Molecular basis for the thiol sensitivity of insulin-degrading enzyme. Proc. Natl. Acad. Sci. USA 105, 9582-9587.

Niwa, T., Naito, C., Mawjood, A.H., and Imai, K. (2000). Increased glutathionyl hemoglobin in diabetes mellitus and hyperlipidemia demonstrated by liquid chromatography/ electrospray ionization-mass spectrometry. Clin. Chem. 46, 82-88.

Obrosova, I.G., Fathallah, L., Liu, E., and Nourooz-Zadeh, J. (2003). Early oxidative stress in the diabetic kidney: effect of DL- $\alpha$-lipoic acid. Free Radic. Biol. Med. 34, 186-195.

Okouchi, M., Okayama, N., Alexander, J.S., and Aw, T.Y. (2006). NRF2-dependent glutamate-L-cysteine ligase catalytic subunit expression mediates insulin protection against hyperglycemiainduced brain endothelial cell apoptosis. Curr. Neurovasc. Res. 3, 249-261.

Omori, K., Ohira, T., Uchida, Y., Ayilavarapu, S., Batista, E.L., Jr., Yagi, M., Iwata, T., Liu, H., Hasturk, H., Kantarci, A., et al. (2008). Priming of neutrophil oxidative burst in diabetes requires preassembly of the NADPH oxidase. J. Leukoc. Biol. 84, 292-301.

Onozato, M.L., Tojo, A., Goto, A., Fujita, T., and Wilcox, C.S. (2002). Oxidative stress and nitric oxide synthase in rat diabetic nephropathy: effects of ACEI and ARB. Kidney Int. 61, 186-194.

Pai, E.F. and Schulz, G.E. (1983). The catalytic mechanism of glutathione reductase as derived from $\mathrm{x}$-ray diffraction 
analyses of reaction intermediates. J. Biol. Chem. 258, 1752-1757.

Pan, S. and Berk, B.C. (2007). Glutathiolation regulates tumor necrosis factor-alpha-induced caspase-3 cleavage and apoptosis: key role for glutaredoxin in the death pathway. Circ. Res. 100, 213-219.

Pellegrini, M., Finetti, F., Petronilli, V., Ulivieri, C., Giusti, F., Lupetti, P., Giorgio, M., Pelicci, P.G., Bernardi, P., and Baldari, C.T. (2007). p66SHC promotes T cell apoptosis by inducing mitochondrial dysfunction and impaired $\mathrm{Ca}^{2+}$ homeostasis. Cell. Death Differ. 14, 338-347.

Penfold, S.A., Coughlan, M.T., Patel, S.K., Srivastava, P.M., Sourris, K.C., Steer, D., Webster, D.E., Thomas, M.C., Maclsaac, R.J., Jerums, G., et al. (2010). Circulating high-molecular-weight RAGE ligands activate pathways implicated in the development of diabetic nephropathy. Kidney Int. 78, 287-295.

Pimentel, D.R., Adachi, T., Ido, Y., Heibeck, T., Jiang, B., Lee, Y., Melendez, J.A., Cohen, R.A., and Colucci, W.S. (2006). Strainstimulated hypertrophy in cardiac myocytes is mediated by reactive oxygen species-dependent Ras S-glutathiolation. J. Mol. Cell Cardiol. 41, 613-622.

Pineda-Molina, E., Klatt, P., Vazquez, J., Marina, A., Garcia de Lacoba, M., Perez-Sala, D., and Lamas, S. (2001). Glutathionylation of the $\mathrm{p} 50$ subunit of NF-kappaB: a mechanism for redox-induced inhibition of DNA binding. Biochemistry 40 , 14134-14142.

Polekhina, G., Board, P.G., Gali, R.R., Rossjohn, J., and Parker, M.W. (1999). Molecular basis of glutathione synthetase deficiency and a rare gene permutation event. EMBO J. 18, 3204-3213.

Qanungo, S., Starke, D.W., Pai, H.V., Mieyal, J.J., and Nieminen, A.L. (2007). Glutathione supplementation potentiates hypoxic apoptosis by S-glutathionylation of p65-NFkappaB. J. Biol. Chem. 282, 18427-18436.

Raha, S., McEachern, G.E., Myint, A.T., and Robinson, B.H. (2000). Superoxides from mitochondrial complex III: the role of manganese superoxide dismutase. Free Radic. Biol. Med. 29, 170-180.

Ristoff, E., Mayatepek, E., and Larsson, A. (2001). Long-term clinical outcome in patients with glutathione synthetase deficiency. J. Pediatr. 139, 79-84.

Rodino-Janeiro, B.K., Gonzalez-Peteiro, M., Ucieda-Somoza, R., Gonzalez-Juanatey, J.R., and Alvarez, E. (2010). Glycated albumin, a precursor of advanced glycation end-products, up-regulates NADPH oxidase and enhances oxidative stress in human endothelial cells: molecular correlate of diabetic vasculopathy. Diabetes Metab. Res. Rev. 26, 550-558.

Ross, W.M., Creighton, M.O., Trevithick, J.R., Stewart-DeHaan, P.J., and Sanwal, M. (1983). Modelling cortical cataractogenesis: VI. Induction by glucose in vitro or in diabetic rats: prevention and reversal by glutathione. Exp. Eye Res. 37, 559-573.

Sabens Liedhegner, E.A., Gao, X.H., and Mieyal, J.J. (2012). Mechanisms of altered redox regulation in neurodegenerative diseases - focus on S-glutathionylation. Antioxid. Redox Signal. 16, 543-566.

Sakai, J., Li, J., Subramanian, K.K., Mondal, S., Bajrami, B., Hattori, H., Jia, Y., Dickinson, B.C., Zhong, J., Ye, K., et al. (2012). Reactive oxygen species-induced actin glutathionylation controls actin dynamics in neutrophils. Immunity 37 , 1037-1049.
Sampathkumar, R., Balasubramanyam, M., Sudarslal, S., Rema, M., Mohan, V., and Balaram, P. (2005). Increased glutathionylated hemoglobin (HbSSG) in type 2 diabetes subjects with microangiopathy. Clin. Biochem. 38, 892-899.

Schmidt, A.M., Hori, O., Chen, J.X., Li, J.F., Crandall, J., Zhang, J., Cao, R., Yan, S.D., Brett, J., and Stern, D. (1995). Advanced glycation endproducts interacting with their endothelial receptor induce expression of vascular cell adhesion molecule-1 (VCAM-1) in cultured human endothelial cells and in mice. A potential mechanism for the accelerated vasculopathy of diabetes. J. Clin. Invest. 96, 1395-1403.

Schuhmacher, S., Oelze, M., Bollmann, F., Kleinert, H., Otto, C., Heeren, T., Steven, S., Hausding, M., Knorr, M., Pautz, A., et al. (2011). Vascular dysfunction in experimental diabetes is improved by pentaerithrityl tetranitrate but not isosorbide-5mononitrate therapy. Diabetes 60, 2608-2616.

Seelig, G.F., Simondsen, R.P., and Meister, A. (1984). Reversible dissociation of gamma-glutamylcysteine synthetase into two subunits. J. Biol. Chem. 259, 9345-9347.

Shelton, M.D., Kern, T.S., and Mieyal, J.J. (2007). Glutaredoxin regulates nuclear factor kappa-B and intercellular adhesion molecule in Muller cells: model of diabetic retinopathy. J. Biol. Chem. 282, 12467-12474.

Shelton, M.D., Distler, A.M., Kern, T.S., and Mieyal, J.J. (2009). Glutaredoxin regulates autocrine and paracrine proinflammatory responses in retinal glial (Muller) cells. J. Biol. Chem. 284, 4760-4766.

Song, P., Wu, Y., Xu, J., Xie, Z., Dong, Y., Zhang, M., and Zou, M.H. (2007). Reactive nitrogen species induced by hyperglycemia suppresses Akt signaling and triggers apoptosis by upregulating phosphatase PTEN (phosphatase and tensin homologue deleted on chromosome 10) in an LKB1-dependent manner. Circulation 116, 1585-1595.

Spielberg, S.P., Garrick, M.D., Corash, L.M., Butler, J.D., Tietze, F., Rogers, L., and Schulman, J.D. (1978). Biochemical heterogeneity in glutathione synthetase deficiency. J. Clin. Invest. 61, 1417-1420.

Starke, D.W., Chock, P.B., and Mieyal, J.J. (2003). Glutathionethiyl radical scavenging and transferase properties of human glutaredoxin (thioltransferase). Potential role in redox signal transduction. J. Biol. Chem. 278, 14607-14613.

Stephens, J.W., Bain, S.C., and Humphries, S.E. (2008). Gene-environment interaction and oxidative stress in cardiovascular disease. Atherosclerosis 200, 229-238.

Suh, Y.A., Arnold, R.S., Lassegue, B., Shi, J., Xu, X., Sorescu, D., Chung, A.B., Griendling, K.K., and Lambeth, J.D. (1999). Cell transformation by the superoxide-generating oxidase Mox1. Nature 401, 79-82.

Sun, W.M., Huang, Z.Z., and Lu, S.C. (1996). Regulation of gammaglutamylcysteine synthetase by protein phosphorylation. Biochem. J. 320, 321-328.

Tagami, S., Kondo, T., Yoshida, K., Hirokawa, J., Ohtsuka, Y., and Kawakami, Y. (1992). Effect of insulin on impaired antioxidant activities in aortic endothelial cells from diabetic rabbits. Metabolism 41, 1053-1058.

Takabe, W., Li, R., Ai, L., Yu, F., Berliner, J.A., and Hsiai, T.K. (2010). Oxidized low-density lipoprotein-activated c-Jun $\mathrm{NH}$ 2-terminal kinase regulates manganese superoxide dismutase ubiquitination: implication for mitochondrial redox status and apoptosis. Arterioscler Thromb. Vasc. Biol. 30, 436-441. 
Tate, S.S. and Meister, A. (1981). gamma-Glutamyl transpeptidase: catalytic, structural and functional aspects. Mol. Cell. Biochem. 39, 357-368.

Thornalley, P., Wolff, S., Crabbe, J., and Stern, A. (1984). The autoxidation of glyceraldehyde and other simple monosaccharides under physiological conditions catalysed by buffer ions. Biochim. Biophys. Acta. 797, 276-287.

Tonks, N.K. (2003). PTP1B: from the sidelines to the front lines! FEBS Lett. 546, 140-148.

Tretter, L. and Adam-Vizi, V. (2004). Generation of reactive oxygen species in the reaction catalyzed by $\alpha$-ketoglutarate dehydrogenase. J. Neurosci. 24, 7771-7778.

Ueda, M., Hung, Y.C., Terai, Y., Kanda, K., Takehara, M., Yamashita, H., Yamaguchi, H., Akise, D., Yasuda, M., Nishiyama, K., et al. (2003). Glutathione S-transferase GSTM1, GSTT1 and p53 codon 72 polymorphisms in human tumor cells. Hum. Cell. 16, 241-251.

van den Berghe, N., Ouwens, D.M., Maassen, J.A., van Mackelenbergh, M.G., Sips, H.C., and Krans, H.M. (1994). Activation of the Ras/mitogen-activated protein kinase signaling pathway alone is not sufficient to induce glucose uptake in 3T3-L1 adipocytes. Mol. Cell. Biol. 14, 2372-2377.

Vanderlaan, M. and Phares, W. (1981). $\gamma$-Glutamyltranspeptidase: a tumour cell marker with a pharmacological function. Histochem. J. 13, 865-877.

Vasquez-Vivar, J., Kalyanaraman, B., and Kennedy, M.C. (2000). Mitochondrial aconitase is a source of hydroxyl radical. An electron spin resonance investigation. J. Biol. Chem. 275, 14064-14069.

Vojtek, A.B. and Der, C.J. (1998). Increasing complexity of the Ras signaling pathway. J. Biol. Chem. 273, 19925-19928.

Wang, J., Pan, S., and Berk, B.C. (2007). Glutaredoxin mediates Akt and eNOS activation by flow in a glutathione reductasedependent manner. Arterioscler. Thromb. Vasc. Biol. 27, $1283-1288$.

Whitfield, J.B. (2001). Gamma glutamyl transferase. Crit. Rev. Clin. Lab. Sci. 38, 263-355.

Whiting, P.H., Kalansooriya, A., Holbrook, I., Haddad, F., and Jennings, P.E. (2008). The relationship between chronic glycaemic control and oxidative stress in type 2 diabetes mellitus. Br. J. Biomed. Sci. 65, 71-74.

Wild, A.C., Moinova, H.R., and Mulcahy, R.T. (1999). Regulation of $\gamma$-glutamylcysteine synthetase subunit gene expression by the transcription factor Nrf2. J. Biol. Chem. 274, 33627-33636.

Wild, S., Roglic, G., Green, A., Sicree, R., and King, H. (2004). Global prevalence of diabetes: estimates for the year 2000 and projections for 2030. Diabetes Care 27, 1047-1053.

Wilhelm, D., Bender, K., Knebel, A., and Angel, P. (1997). The level of intracellular glutathione is a key regulator for the induction of stress-activated signal transduction pathways including Jun $\mathrm{N}$-terminal protein kinases and p38 kinase by alkylating agents. Mol. Cell. Biol. 17, 4792-4800.

Williams, C.H., Jr. (1976). Flavin-containing dehydrogenases. In: The enzymes, P.D. Boyer, 3rd ed. Chapter 3.IV (New York: Academic Press), pp. 129-142.

Wolff, S.P. and Dean, R.T. (1987). Glucose autoxidation and protein modification. The potential role of 'autoxidative glycosylation' in diabetes. Biochem. J. 245, 243-250.

Yang, H., Magilnick, N., Lee, C., Kalmaz, D., Ou, X., Chan, J.Y., and Lu, S.C. (2005). Nrf1 and Nrf2 regulate rat glutamate-cysteine ligase catalytic subunit transcription indirectly via NF- $\mathrm{KB}$ and AP-1. Mol. Cell. Biol. 25, 5933-5946.

Yerneni, K.K., Bai, W., Khan, B.V., Medford, R.M., and Natarajan, R. (1999). Hyperglycemia-induced activation of nuclear transcription factor $\kappa B$ in vascular smooth muscle cells. Diabetes 48, 855-864.

Yoon, K.H., Lee, J.H., Kim, J.W., Cho, J.H., Choi, Y.H., Ko, S.H., Zimmet, P., and Son, H.Y. (2006). Epidemic obesity and type 2 diabetes in Asia. Lancet 368, 1681-1688.

Yoshitake, S., Nanri, H., Fernando, M.R., and Minakami, S. (1994). Possible differences in the regenerative roles played by thioltransferase and thioredoxin for oxidatively damaged proteins. J. Biochem. 116, 42-46.

Zhang, H., Forman, H.J., and Choi, J. (2005). Gamma-glutamyl transpeptidase in glutathione biosynthesis. Methods Enzymol. 401, 468-483.

Zmijewski, J.W., Banerjee, S., and Abraham, E. (2009). S-glutathionylation of the Rpn2 regulatory subunit inhibits $26 \mathrm{~S}$ proteasomal function. J. Biol. Chem. 284, 22213-22221. 


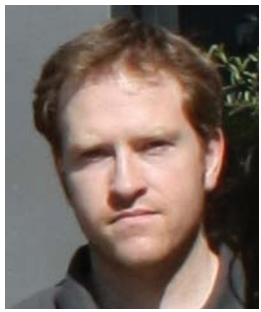

Francisco Javier Sánchez Gómez: Biology degree, Universidad Complutense de Madrid (UCM), specialist in Genetics, 2003. Internal student at Department of Genetics, UCM, 2002. PhD degree by UCM in Biochemistry and Molecular Biology, 2008 at the Dr. Pérez-Sala laboratory in the Centro de Investigaciones Biológicas-CSIC. Junior Researcher in the company "Projech Science to Technology S.L.” 2008. Postdoctoral fellow at Centro de Biología Molecular "Severo Ochoa" (CBMSO), 2010. Short stay at Prof. Antonio García de Herreros laboratory in Universidad Pompeu Fabra, Barcelona, 2005. Short stay at Dr. Madhu Dikshit laboratory, Central Drug Research Institute-CSIR, Lucknow, India, 2012.

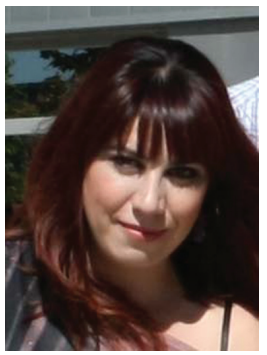

María Cristina Espinosa: Biochemistry degree 2009 by Universidad Complutense de Madrid, Spain. Internal student in Dr. Maria Angeles Navas laboratory in Universidad Complutense School of Medicine 2009. Master degree in Biochemistry and Molecular Biology 2010 in Universidad Complutense de Madrid, Spain. PhD Student in Dr. Santiago Lamas laboratory since March 2010 in Centro de Biología Molecular Severo Ochoa, Madrid, Spain. Short stay in Dr. Madhu Dikshit laboratory, Central Drug Research Institute. Lucknow, India, two weeks February 2012. Short stay in Carlos Fernandez-Hernando laboratory in New York University, New York, USA, from July to October 2012.

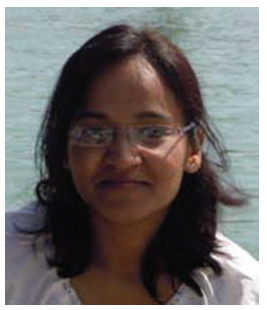

Megha Dubey: Bachelor Science degree Banasthali University, India, 2009. Junior Reseach Fellowship at Dr. Dikshit laboratory, Cardiovascular Unit, Pharmacology Division of CDRI-CSIR, Lucknow, India, since 2010 until the present. Short stay at Prof. Santiago Lamas laboratory, at CBMSO-CSIC, Madrid, Spain, 2011.

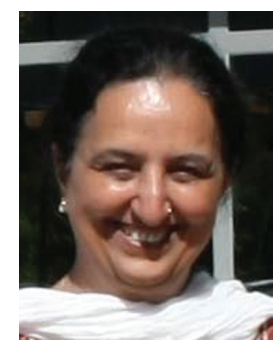

Madhu Dikshit BSc Degree, Allahabad University 1975, Botany, Zoology, Chemistry. MSc Degree, Allahabad University 1977, Biochemistry. PhD Degree, Kanpur University, 1983, Chemistry. Chief Scientist and Head of Pharmacology Division of CSIR-Central Drug Research Institute, Lucknow. Area coordinator CVS-CNS and related disorder. Principal Investigator of the National Project on "Development of Potential Drugs from the Ocean" Sponsored by Ministry of Earth Sciences (14 National labs from various Institutes/ Universities are participating in this project). Professor K.P. Bhargava Memorial Medal (1999) from Indian National Science Academy, New Delhi, for 1999. Invited Senior Scientist Position award by French Ministrere de la Recherché for three months (1st October to 31st December, 2000), at a CNRS, Lab Faculty of Medicine Nancy, France. National Bioscience Award, by the Department of Biotechnology, Ministry of Science \& Technology for 2000. Dr. N. S. Dhalla Oration, of Indian Pharmacological Society for contribution in Cardiovascular Sciences, 2006. Vigyan Ratna, of UP-CST for significant contribution in Biological Sciences, 2009-2010. Member of the Annals of Neurosciences, Drugs and Pharmaceuticals Industry Highlights, Indian Journal of Pharmacology, and Proceedings of the National Academy of Sciences editorial Boards.

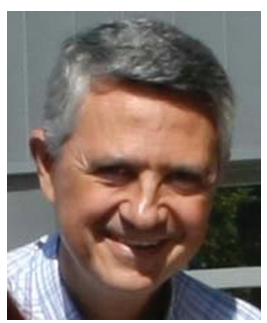

Santiago Lamas MD Degree, Universidad Autónoma de Madrid (UAM) 1981. Specialist in Nephrology, Hospital "Ramón y Cajal” 1986. PhD degree, UAM (Physiology) 1989. Postdoctoral fellow Brigham \& Women's Hospital, Harvard Medical School 1990-1992. Staff member of the Spanish National Research Council (CSIC) since 1993. Research Professor and Group Leader (Pathophysiology of the vascular endothelium) at Centro de Biologia Molecular "Severo Ochoa" (CBMSO). Director of CBMSO since 2012. Member of the board of trustees of the Fundación Renal Iñigo Alvarez de Toledo. President of the Spanish Group of Research in Free Radicals (GEIRLI) from 2004-2007. Coordinator of the CONSOLIDER Program Project "Reactive oxygen species and systems". Coordinator of the R \& D in Biomedicine Program Project FIBROTEAM for the study of Tissue and Organ Fibrosis. Circa 7000 citations in more than 125 original articles. Personal H-Index $=40$ (Jan. 2013). In addition to being Associate Editor of Redox Biology, also a member of the editorial board of the journals Cardiovascular Research, Free Radical Biology \& Medicine, Free Radical Research, and Nitric Oxide. Evaluator and assessment expert for the principal Funding Agencies in Spain, Argentina, United Kingdom and the European Commission. 